\title{
Efficacy, safety, and quality-of-life of treatments for acute relapses of multiple sclerosis: results from a literature review of randomized controlled trials
}

This article was published in the following Dove Press journal:

Degenerative Neurological and Neuromuscular Disease

\author{
Jessica Costello' \\ Annete Njue ${ }^{\prime}$ \\ Matthew Lyall' \\ Anne Heyes' \\ Nancy Mahler ${ }^{2}$ \\ Michael Philbin ${ }^{2}$ \\ Tara Nazareth ${ }^{3}$ \\ 'Health Economics and Outcome \\ Research/ Health Technology Assessment \\ Services, RTI Health Solutions, \\ Manchester, M20 2LS, UK; ${ }^{2}$ Health \\ Economics and Outcome Research- \\ Medical Science Liaison, Mallinckrodt \\ Pharmaceuticals, Bedminister, NJ 0792I, \\ USA; ${ }^{3}$ Health Economics and Outcome \\ Research, Mallinckrodt Pharmaceuticals, \\ Bedminister, NJ 0792I, USA
}

Background: Intravenous methylprednisolone (IVMP), repository corticotropin injection (RCI), plasmapheresis (PMP), and intravenous immunoglobulin (IVIG) are used in the treatment of acute multiple sclerosis (MS) relapse. A systematic literature review (SLR) of randomized controlled trials (RCTs) was conducted to examine the highest quality evidence available for these therapies.

Methods: English-language articles were searched in MEDLINE, Embase, and Cochrane Library through May 2016 per Preferred Reporting Items for Systematic Reviews and MetaAnalyses standards. MS conferences, SLRs, and bibliographies of included studies were also searched. Eligible studies included adults treated with $\geq 1$ aforementioned therapy.

Results: Twenty-three RCTs were identified: 22 on efficacy, 11 on safety, and 3 on QOL (ie 18 IVMP, 2 RCI, 2 PMP, and 2 IVIG). IVMP and RCI improved relapse-related disability; however, IVIG and PMP showed inconsistent efficacy. QOL data were only ascertained for IVMP.

Conclusions: RCTs indicate IVMP and RCI are efficacious and well tolerated treatments for MS relapse. Overall, many RCTs were dated, with sample sizes of fewer than 30 patients and no definitions for relapse nor clinically significant change. Contemporary evidence generation for all relapse treatments of interest, across efficacy, safety, and QOL outcomes, is still needed.

Keywords: multiple sclerosis relapse, efficacy, safety, systematic literature review

\section{Introduction}

\section{Multiple sclerosis and relapses}

Multiple sclerosis (MS) is one of the most common causes of disability in young adults. ${ }^{1}$ The most characteristic clinical feature of the disease is the occurrence of relapses or exacerbations. ${ }^{2}$ Relapses are typically defined as episodes of focal neurological disturbance lasting more than $24 \mathrm{hrs}$ without an alternate explanation and must be separated from the previous episode by a period of 30 days. They are associated with increased sustained functional impairment and decreased quality of life (QOL) in untreated patients. ${ }^{3}$ Notably, progressive worsening may occur with incomplete recovery from these exacerbations. ${ }^{3}$

Costello Health Economics and Outcome Research/Health Technology Assessment Services, RTI Health Solutions, Wilmslow Road, The Pavilion, Towers Business Park, Manchester M20 2LS, UK

Tel +44 I6I 4476000

Email jcostello@rti.org

\section{Treatment of relapses}

Real-world treatment patterns observed in patients experiencing acute MS relapse within the United States indicate that various management options may be used, 
including corticosteroids (CS; such as high-dose intravenous methylprednisolone [IVMP]), repository corticotropin injection (RCI), plasmapheresis (PMP), and intravenous immunoglobulin (IVIG). ${ }^{4}$ Table 1 presents expert statements from US-based MS organizations relating to the therapeutic management of relapses in MS.

Intravenous methylprednisolone is an anti-inflammatory glucocorticosteroid that is indicated by the United States (US) Food and Drug Administration (FDA) for the treatment of MS relapse. ${ }^{5} \mathrm{RCI}$, also known as H.P. Acthar Gel, is a subcutaneous (SC) or intramuscular (IM) injection of adrenocorticotropic hormone (ACTH) approved by the FDA for use in patients experiencing MS relapse. ${ }^{6}$ PMP is a medical procedure that has been recommended for steroid-resistant acute MS relapses by the American Academy of Neurology (Table 1) and American Society for Apheresis (ASFA). ${ }^{7,8}$ IVIG is an administered treatment comprised of pooled immunoglobulin $\mathrm{G}(\operatorname{IgG})$ prepared from the fractionation of human plasma, and is also used in the treatment of MS relapse ${ }^{9}$ despite not having an FDA indication for such use ${ }^{10}$ and having insufficient supporting evidence by expert organizations AAN and NMSS, except for extenuating circumstance, such as pregnancy. ${ }^{7}$

Past studies have shown that a proportion of patients report worsened symptoms or no treatment effect with
CS. ${ }^{11}$ For such patients who do not tolerate or respond well to CS, escalating treatment of relapse-in which a second course of high-dose IVMP or a non-CS treatment is given - has become more common. ${ }^{12}$ In keeping, a treatment algorithm for MS relapse has been proposed, ${ }^{13}$ in which IVMP is recommended as first-line treatment, RCI as an option for patients who do not improve with or cannot tolerate IVMP, and PMP for patients with disabling symptoms that do not respond to initial treatment.

As such, a systematic literature review (SLR) was undertaken to examine all published scientific information available for these therapies, focusing on randomized controlled trials in order to reflect the highest quality of evidence.

\section{Objectives}

To systematically evaluate the literature on the efficacy, safety, and quality-of-life (QOL) data for IVMP, RCI, PMP, and IVIG when used in the treatment of acute MS relapses. Randomized controlled trials (RCTs) were utilized to reflect the highest standards of study design and execution and the highest quality of evidence.

\section{Methods}

The review was conducted according to the widely recognized standards of Preferred Reporting Items for

Table I Expert statements from US MS Organizations on MS relapse treatments

\begin{tabular}{|c|c|c|c|}
\hline Treatment & Approved $^{a}$ & National Multiple Sclerosis Society ${ }^{14,15}$ & American Academy of Neurology $y^{7,16}$ \\
\hline IVMP & Yes & $\begin{array}{l}\text { CS are the accepted standard of care. The steroid most } \\
\text { often used is IVMP. }\end{array}$ & $\begin{array}{l}\text { CS have been demonstrated to have a short-term } \\
\text { benefit on the speed of functional recovery in } \\
\text { patients with acute attacks of MS. }\end{array}$ \\
\hline $\mathrm{RCl}$ & Yes & $\begin{array}{l}\mathrm{RCl} \text { is shown to be as effective as IVMP and may have a } \\
\text { place in situations where IV infusion is impractical or posi- } \\
\text { tive effects on bone via stimulation of dehydroepiandros- } \\
\text { terone and mineralocorticoids may be desirable. }\end{array}$ & Not mentioned \\
\hline PMP & $\begin{array}{l}\text { Not } \\
\text { reviewed }\end{array}$ & Second-line treatment for steroid-resistant exacerbations. & $\begin{array}{l}\text { May be helpful in the treatment of severe acute } \\
\text { episodes of demyelination in previously nondisabled } \\
\text { individuals. }\end{array}$ \\
\hline IVIG & $\mathrm{No}^{\mathrm{b}}$ & $\begin{array}{l}\text { IVIG may be considered for relapses during pregnancy } \\
\text { (during which time steroids should be avoided if possible, } \\
\text { except in severe cases where required) IVIG is also some- } \\
\text { times used to treat relapses that do not respond to CS, } \\
\text { although the supportive evidence is limited. }\end{array}$ & $\begin{array}{l}\text { There are insufficient data to support the use of IVIG } \\
\text { as monotherapy for MS relapses. }\end{array}$ \\
\hline
\end{tabular}

Notes: ${ }^{a}$ Approved and indicated for use by the US FDA; procedures such as plasmapheresis are not reviewed by FDA. ${ }^{\mathrm{b}}$ Reviewed by the FDA but not approved for treatment of MS relapse.

Abbreviations: CS, corticosteroids; FDA, US Food and Drug Administration; IVIG, intravenous immunoglobulin; IVMP, intravenous methylprednisolone; MS, multiple sclerosis; N/A, not applicable; PMP, plasmapheresis; $\mathrm{RCl}$, repository corticotropin injection; US, United States. 
Systematic Reviews and Meta-Analyses (PRISMA), developed to ensure rigorous and unbiased reporting internationally.

\section{Literature search and data extraction}

Searches for English-language articles were performed in the following electronic databases: MEDLINE, MEDLINE InProcess, Embase, Biosciences Information Service (BIOSIS), and The Cochrane Library. No date limit was applied; searches were conducted from database inception to May 1, 2016. (See Table S1 for MEDLINE search strategy.)

Relevant conference abstracts (American Academy of Neurology [AAN], Americas Committee for Treatment and Research in Multiple Sclerosis [ACTRIMS], and European Committee for Treatment and Research in Multiple Sclerosis [ECTRIMS]) were also searched, given their tendency to carry contemporary clinical information prior to or supplementary to publication: ACTRIMS and ECTRIMS 20132016 and AAN 2014-2016. Bibliographic lists of recent relevant SLRs and meta-analyses selected for inclusion were searched for further studies of interest.

Search terms included combinations of free text and Medical Subject Headings (MeSH) for MS disease terms. The search was restricted using MeSH terms and title and abstract terms for interventions of interest: ACTH, IVMP, IVIG, and PMP. The search was also restricted to RCTs using terms for these study types. The search strategy for PubMed is shown in the Supplementary Material Appendix A.

Inclusion or exclusion of studies was assessed independently in two steps by two researchers. In step 1, titles and abstracts of all identified articles were reviewed for eligibility according to the prespecified inclusion and exclusion criteria. The full texts of articles selected at step 1 were reviewed for eligibility at step 2 . At each step, any discrepancies were resolved by consensus, with input from a senior researcher if necessary. Articles were included at step 1 if they described studies evaluating the treatments of interest in patients aged 18 years or older; at step 2, articles were included if they reported outcomes of interest, informating efficacy, safety, and QOL. 'Please note: the search was initially designed to identify randomized and nonrandomized trials and prospective and retrospective studies; however, for the purposes of this manuscript, which focuses on RCTs, selection of full texts during level 2 screen was limited to RCTs only). Non-US studies of treatments of interest IVMP, PMP, and IVIG were included if they met the relevant inclusion criteria, as formulations of these products used outside the US are comparable to those used within the US. Given RCI is a natural formulation of ACTH only available in the US, only US studies relating to RCI were included.

One researcher extracted data; an independent reviewer quality checked all data, including verification of the data with the original source.

\section{Data synthesis}

Information extracted from eligible studies was presented in detailed evidence tables, and an overview of the findings of the eligible studies was reported. No statistical analyses were performed on the data. Qualitative conclusions were reported based on identified studies. Baseline versus follow-up results for the treatments of interest were examined to describe treatment efficacy. When the treatment of interest was not available alone but as a combination therapy, treatment arms were compared to informally assess the treatment's individual efficacy if the study design allowed.

In studies in which a definition of significant change for outcomes of interest was not specified by the authors, a generally accepted definition available in the literature was applied for the purposes of interpretation. When this definition could not be applied (eg when measurement of change required knowledge of baseline outcome data not presented in the publication), the authors' conclusions are presented with the caveat that a definition of significant change was not specified. In the data tables, wording used in the publications is presented along with the stated definitions of significant change.

For the purposes of this SLR, we considered that results beyond 3 months of the relapse were less relevant to acuteMS relapse; therefore, we did not focus on such long-term effects of acute therapy here.

Study sample sizes of fewer than 30 patients were consistently referred to as small. ${ }^{17}$

\section{Quality assessment}

The quality assessment of each study was performed to standards recommended by the National Institute for Health and Care Excellence (NICE). ${ }^{18,19}$ These are based on eight questions assessing the risk of bias and generalizability of the studies and how study information is used in any data synthesis. NICE processes are based on robust methodology and are consequently used on an international level, allowing for consistency and reproducibility of results. 


\section{Results}

\section{Description of included studies and reported outcomes}

A total of 1,736 articles was identified and screened for eligibility. Of these, 23 unique studies met the eligibility criteria and were selected for inclusion (Figure 1).

The "other" listed in the field "records excluded" refers to the "other" category for exclusion, this relates to publications that were duplicates of other hits, as well as nonEnglish papers.

Available evidence according to treatment of interest is shown in Table 2. These studies included monotherapies as well as combination therapies.

\section{Efficacy outcomes}

Of the 23 RCTs included, 22 reported efficacy using the Disability Status Scale (DSS) or the Expanded Disability Status Scale (EDSS) score. The DSS is a method of quantifying and monitoring changes in the level of disability over time and is primarily based on physical functioning and ability to walk. ${ }^{20}$ Over time, this scale has been modified several times to more accurately reflect the levels of disabilities clinically observed and was renamed EDSS. ${ }^{21}$ A change of $\geq 1$ in EDSS score is generally accepted as a clinically significant change for patients with baseline EDSS of 5.5 or lower or 0.5 points in patients with a higher EDSS score. ${ }^{22}$ Therefore, for the purposes of interpretation in the narrative of this SLR, this definition was applied in studies in which a definition of improvement was not specified by the authors; when this definition could not be applied, the authors' conclusions were presented with the caveat that a definition of clinically significant change was not specified.

\section{Intravenous methylprednisolone}

A total of 17 RCTs evaluated IVMP treatment, using different dosing regimens, administration methods, comparator therapies, or combination therapy regimens. The majority of the studies included sample sizes that are less

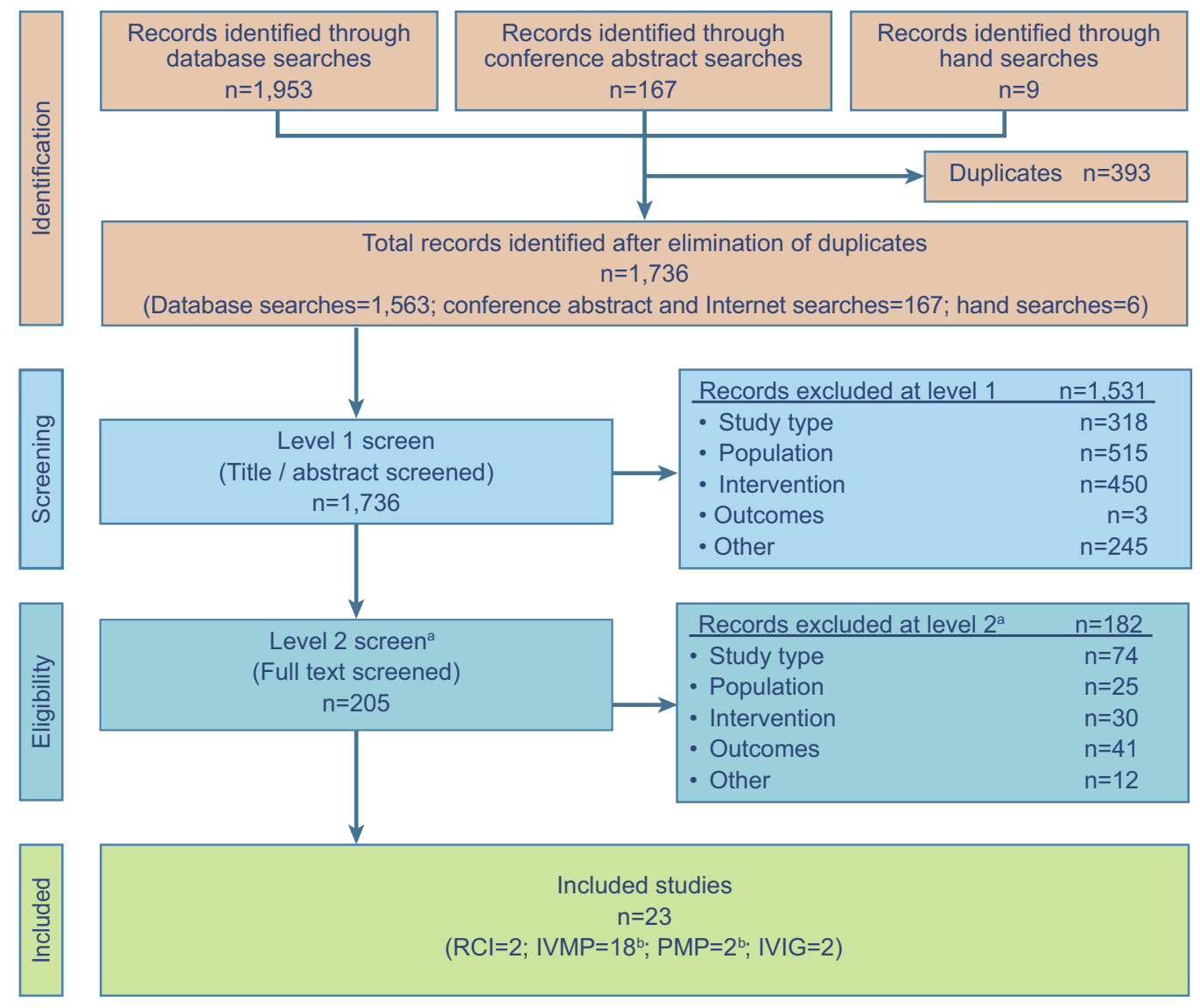

Figure I PRISMA diagram for study inclusion and exclusion. ${ }^{\mathrm{a} A}$ focus on RCTs was imposed at level 2 screening. All other study types were excluded (ie, publications that were duplicates, non-English publications). ${ }^{\text {} O n e ~ R C T ~ c o m p a r e d ~ t w o ~ t r e a t m e n t s ~ o f ~ i n t e r e s t: ~ I V M P ~ v e r s u s ~ P M P . ~}$

Abbreviations: IVIG, intravenous immunoglobulin; IVMP, intravenous methylprednisolone; PMP, plasmapheresis; RCl, repository corticotropin injection; RCT, randomized controlled trial; PRISMA, Preferred Reporting Items for Systematic Reviews and Meta-Analyses. 
Table 2 Overview of studies

\begin{tabular}{|l|l|l|l|l|}
\hline Treatment & Number of RCTs & Efficacy & Safety & QOL \\
\hline RCI & 2 & 2 & 2 & 0 \\
IVMP & $18^{\mathrm{a}}$ & 17 & 7 & 3 \\
PMP & $2^{\mathrm{a}}$ & 2 & 0 & 0 \\
IVIG & 2 & 2 & 2 & 0 \\
Total & 23 & 22 & $\mathrm{II}$ & 3 \\
\hline
\end{tabular}

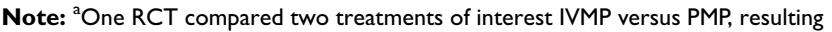
in 23 (rather than 24) unique studies.

Abbreviations: IVIG, intravenous immunoglobulin; IVMP, intravenous methylprednisolone; PMP, plasmapheresis; $\mathrm{QOL}$, quality of life; $\mathrm{RCl}$, repository corticotropin injection; RCT, randomized clinical trial.

than 100. Results largely demonstrated efficacy via improved relapse-related disability (ie DSS/EDSS score). These results are presented in Sections 3.2.1.1 to 3.2.1.4.

Two additional studies of IVIG included subsequent IVMP within the regimen; these are presented with IVIG studies in Section 3.2.2.
Intravenous methylprednisolone versus placebo

Four RCTs compared IVMP versus placebo (Table 3), with the total number of study patients included ranging from 20 to 44 and a smaller sample size corresponding to the IVMP study arm ranging from 12-22.

Only 1 study provided a definition of relapse, ${ }^{23}$ described as the occurrence of one or more new symptoms or worsening of existing symptoms for a duration of $<8$ weeks but $>24$ hrs which had not improved spontaneously at the time of entry into the trial.

Clinically significant improvement was defined as a gain of $\geq 1$ point on the EDSS in 3 of the 4 studies; by this measure, the studies showed improvement in patients experiencing acute MS relapses who were treated with IVMP for 5 days $^{23}$ or 15 days. $^{24,25}$ The remaining study showed a mean difference of 1 in the IVMP group and a difference of 0 in the placebo group; no definition of clinically significant change was provided for either group; however, meaningful change

Table 3 Intravenous methylprednisolone versus placebo

\begin{tabular}{|c|c|c|}
\hline Study/N/Age/Location & $\begin{array}{l}\text { Intervention and treatment } \\
\text { duration }\end{array}$ & Summary of efficacy results \\
\hline $\begin{array}{l}\text { Durelli et al }(1985)^{24} \\
\mathrm{~N}=20 \\
\text { Mean age, years: } 32.1 \\
\text { Italy }\end{array}$ & $\begin{array}{l}\text { Intervention } \\
\text { IVMP }(n=12) \text { vs placebo }{ }^{a}(n=8) \\
\text { Treatment duration } \\
\text { IVMP/placebo: I5 days } \\
\text { Assessments } \\
\text { Daily for } 15 \text { days }\end{array}$ & $\begin{array}{l}\text { Clinically significant EDSS score improvement ( } \geq 1 \text { point): } \\
\text { IVMP, II/I } 2 \text { patients, } 3-6 \text { days after IVMP administration } \\
\text { Placebo: } 3 / 8 \text { patients, } 5-14 \text { days after placebo administration }\end{array}$ \\
\hline $\begin{array}{l}\text { Durelli et al }(1986)^{25} \\
\mathrm{~N}=23 \\
\text { Mean age, years: MP, } 30.7 \text {; placebo, } \\
33.9 \\
\text { Italy }\end{array}$ & $\begin{array}{l}\text { Intervention } \\
\text { IVMP }(n=13) \text { vs Placebo }(n=10) \\
\text { Treatment duration } \\
\text { IVMP/placebo: } 15 \text { days } \\
\text { Assessments } \\
\text { Daily for } 15 \text { days }\end{array}$ & $\begin{array}{l}\text { Clinically significant EDSS score improvement ( } \geq 1 \text { point): } \\
\text { Day 5: IVMP, } 8 / 1 \text { I patients; placebo, I/I0 patients } \\
\text { Day I0: IVMP, I0/II patients; placebo, I/I0 patients } \\
\text { Day I5: IVMP, I0/II patients; placebo, } 4 / 10 \text { patients }\end{array}$ \\
\hline $\begin{array}{l}\text { Filipovic et al }(1997)^{26} \\
\mathrm{~N}=44 \\
\text { Mean age, years: group P, 35.3; } \\
\text { group M, 3I.6 } \\
\text { Yugoslavia }\end{array}$ & $\begin{array}{l}\text { Intervention } \\
\text { IVMP }(n=22) \text { vs placebo }(n=22) \\
\text { Treatment duration } \\
5 \text { days } \\
\text { Assessments } \\
\text { I day before and } 2 \text { days after treat- } \\
\text { ment completion }\end{array}$ & $\begin{array}{l}\text { Mean difference between EDSS scores I day before and } 2 \text { days after } \\
\text { treatment completion: } \\
\text { IVMP: } 1.00 \text { improvement } \\
\text { Placebo: } 0.0 \\
(P<0.000 I)\end{array}$ \\
\hline $\begin{array}{l}\text { Milligan et al }(1987)^{23} \\
\mathrm{~N}=22 \\
\text { Age, years: acute relapse, } 34.1 \text {; } \\
\text { progressive, } 39.8 \\
\text { United Kingdom }\end{array}$ & $\begin{array}{l}\text { Intervention } \\
\text { IVMP }(n=13) \text { vs placebo }(n=9) \\
\text { Treatment duration } \\
5 \text { days } \\
\text { Assessments } \\
\text { Weeks I and } 4 \text { after treatment onset }\end{array}$ & $\begin{array}{l}\text { EDSS score improvement ( } \geq \text { I-point): } \\
\text { Week I: IVMP, } 8 / 13 \text { patients; placebo, I/9 patients } \\
\text { Week 4, IVMP, I0/I3 patients; placebo, } 2 / 8 \text { patients }\end{array}$ \\
\hline
\end{tabular}

Note: ${ }^{a}$ After 15 days of treatment with IVMP vs placebo (randomized phase), patients in both groups received OPT, which was slowly tapered over 120 days.

Abbreviations: EDSS, Expanded Disability Status Scale; IVMP, intravenous methylprednisolone; MP, methylprednisolone; NR, not reported; OPT, oral prednisone taper. 
can be inferred by utilizing the accepted definition of clinically significant improvement. ${ }^{26}$

Studies comparing different doses of intravenous methylprednisolone

Four RCTs compared different doses of IVMP (Table 4), with total sample sizes ranging from 24 to 31 . A definition of relapse was reported in 3 of 4 studies; 2 studies defined a relapse as the appearance or the worsening of symptoms lasting for at least $24 \mathrm{hrs}$ and causing an increase of disability of at least 1 point on the EDSS in the absence of concomitant fever. ${ }^{27,28}$ The same definition was reported in the third study, with a timeframe of 6 days to 4 weeks. ${ }^{29}$

EDSS scores improved versus baseline in both lowdose and high-dose IVMP groups; different studies demonstrated varying frequency of improvement and extent of recovery at varying time points. ${ }^{27-30}$

One study reported a score improvement of $\geq 1$ EDSS score change as a therapeutic improvement. ${ }^{29}$ Although a definition of EDSS clinically significant change was not explicitly provided in the three remaining studies, 2 of these reported significant improvement; ${ }^{27,28}$ the remaining study did not report clinical significance of results. Further, the generally accepted definition of clinically significant change ( $\geq 1$-point EDSS score change in patients with baseline EDSS $<5.5$ ) could be applied to one of these studies, demonstrating a clinically significant change in EDSS at 7 days (T7) versus baseline in patients treated with high-dose IVMP. ${ }^{28}$

\section{Intravenous methylprednisolone (Different settings)}

A study conducted in the United Kingdom (UK) reported EDSS outcomes of 138 patients experiencing MS relapses treated in an outpatient or home setting (Table 5). ${ }^{31}$ A definition of relapse was not provided. The outpatient treatment group showed an improvement of 0.8 in the EDSS score at week 6 versus baseline and the home group 1.0; only the latter met the standard clinical improvement definition of a 1point improvement. ${ }^{22}$

Intravenous methylprednisolone daytime versus nighttime administration

One single-center, pilot RCT reported EDSS outcomes of 17 patients with MS relapses treated with IVMP administered during the day or night. ${ }^{32} \mathrm{~A}$ definition of relapse was not provided. The study was based on the premise that MS is associated with diurnal variations in symptoms and that chronotherapy, a treatment regimen tailored to diurnal body rhythms, may increase the efficacy, safety, and tolerability of treatment. ${ }^{32}$ Clinical improvement following treatment, as measured using EDSS, was reported in both groups versus baseline; no magnitude of improvement was available. At day 7 , the nighttime group experienced at least a 2 point reduction in EDSS (Table 6) exceeding the standard definition of a clinically significant improvement (gain of $\geq 1$ point in patients with baseline EDSS $\leq 5.5$ or gain of $\geq 0.5$ in patients with baseline EDSS $>5.5 .5),{ }^{22}$ no results were available for the daytime group at Day 7 .

Intravenous methylprednisolone followed by oral prednisone taper either alone or concomitant with PMP or IA One pilot RCT reported EDSS outcomes of 17 patients with MS relapses treated with IVMP followed by oral prednisone taper (OPT) alone, in combination with PMP, and in combination with immunoadsorption (IA) (Table 7). ${ }^{33}$ A definition of clinical improvement or relapse was not provided. IVMP followed by OPT and IVMP followed by OPT and in combination with PMP or IA were shown to reduce disability in patients with MS relapses at the 2-week assessment versus baseline; however, when applying the standard definition of clinically significant change, ${ }^{22}$ the group receiving IVMP followed by OPT who were not receiving additional therapy did not experience clinically significant improvement at 2 weeks or 3 months follow-up.

Intravenous methylprednisolone versus oral methylprednisolone

Five studies evaluated IVMP versus oral methylprednisolone (OMP) (Table 8). A definition of relapse was not reported in any of the studies. Four of the 5 studies showed efficacy with IVMP; the baseline EDSS with which to qualify clinically significant change in the remaining study was unclear, complicating interpretation. Three of the 4 positive studies had small sample sizes, ranging from 20-24 patients in the IVMP arm.

Two of the studies provided a definition of clinically significant EDSS change ( $\geq 1$ score change) and reported a clinically significant improvement for both IVMP and OMP. $^{34,35}$ Of the 3 studies that did not provide a definition of clinical significance in EDSS score change, the standard definition of a clinically significant EDSS improvement (a 1 or 0.5 unit increase in EDSS vs baseline in patients with baseline EDSS score of $\leq 5.5$ or $>5.5$, respectively ${ }^{22}$ ) could be applied to two of them. ${ }^{36,37}$ In one of these, a clinically significant change was seen at 4 and 12 weeks, with both IVMP and OMP. ${ }^{36}$ In the other, IVMP did not show a clinically significant improvement at week 1 but did at 


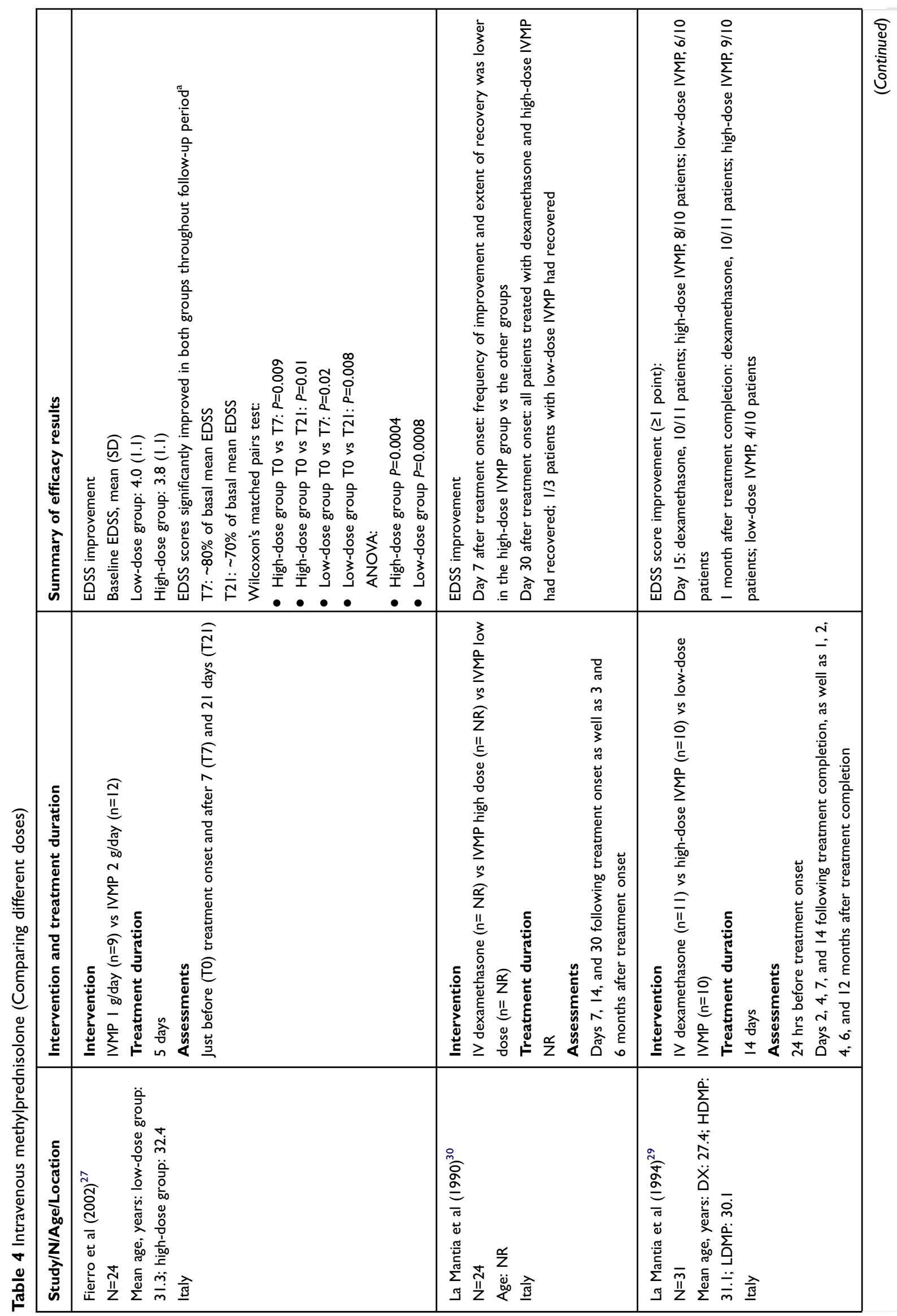



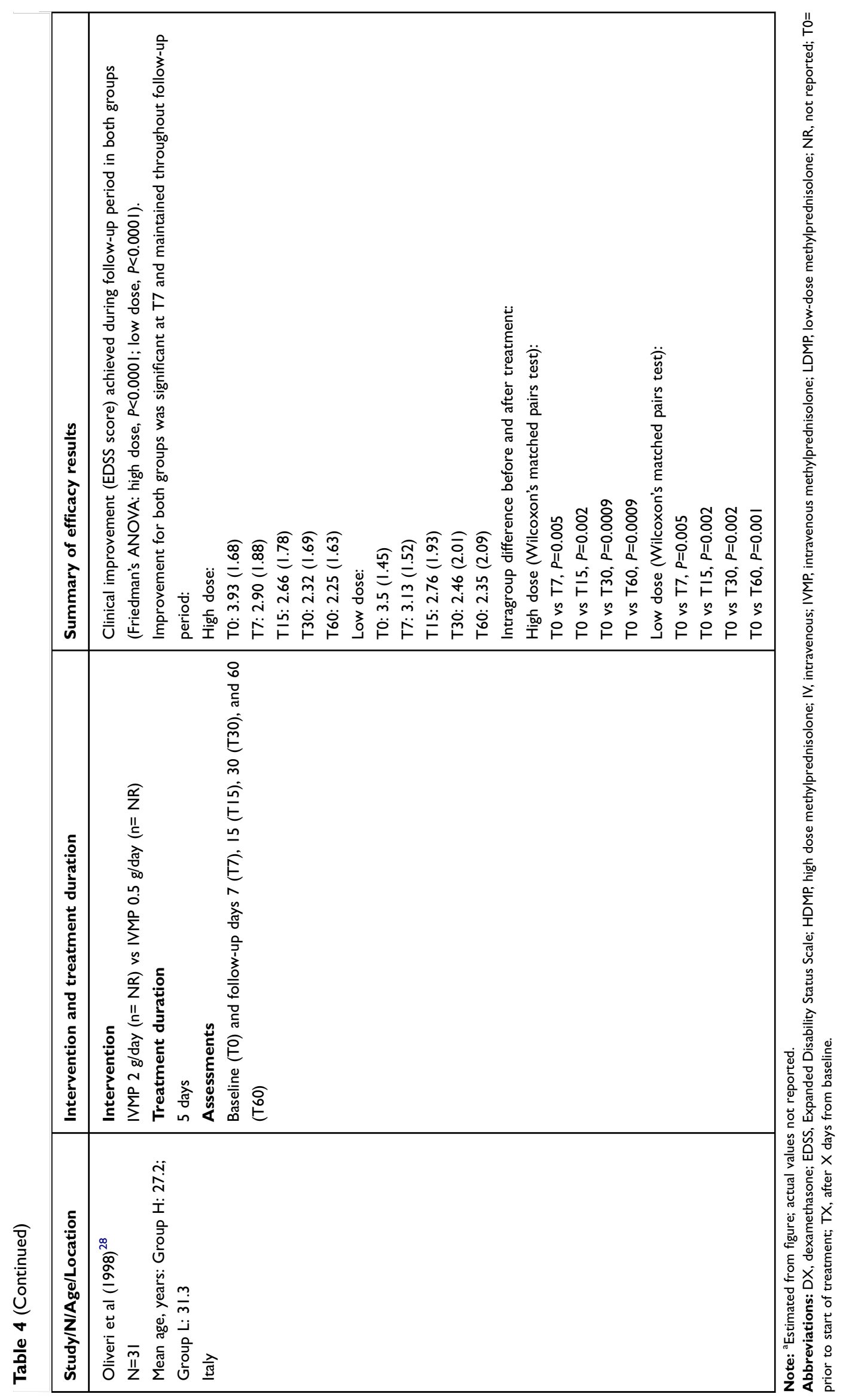
Table 5 Intravenous methylprednisolone (different settings)

\begin{tabular}{|c|c|c|}
\hline Study/N/Age/Location & Intervention and Treatment Duration & Summary of Efficacy Results \\
\hline $\begin{array}{l}\text { Chataway et al }(2006)^{31} \\
\mathrm{~N}=138 \\
\text { Mean age, years: outpatient treatment: } 40.4 \text {; home } \\
\text { treatment: } 36.8 \\
\text { UK }\end{array}$ & $\begin{array}{l}\text { Intervention } \\
\text { IVMP outpatient setting }(n=69) \text { vs IVMP home } \\
\text { setting }(n=69) \\
\text { Treatment duration } \\
3 \text { days } \\
\text { Assessments } \\
\text { Baseline and } 6 \text { weeks later }\end{array}$ & $\begin{array}{l}\text { Mean EDSS score } \\
\text { Baseline: } \\
\text { Outpatient, } 5.2 \text { (I.3) } \\
\text { Home, } 5.2(1.5) \\
6 \text { weeks: } \\
\text { Outpatient, } 4.4 \text { (I.9) } \\
\text { Home, } 4.1 \text { ( } 2.0) \\
\text { Mean EDSS score improvement at week } 6 \\
\text { vs baseline: } \\
\text { Outpatient, } 0.8 \text {; home, I.0 (difference, } \\
0.2 ; P=0.32 \text { I) }\end{array}$ \\
\hline
\end{tabular}

Abbreviations: EDSS, Expanded Disability Status Scale; IVMP, intravenous methylprednisolone; NR, not reported; UK, United Kingdom.

Table 6 Intravenous methylprednisolone (administered at different times)

\begin{tabular}{|c|c|c|}
\hline $\begin{array}{l}\text { Study/N/Age/ } \\
\text { Location }\end{array}$ & Intervention and treatment duration & Summary of efficacy results \\
\hline $\begin{array}{l}\text { Glass-Marmor et al } \\
(2007)^{32} \\
\mathrm{~N}=17 \\
\text { Mean age, years: day- } \\
\text { time: } 35.4 \text {; nighttime: } \\
35.1 \\
\text { Israel }\end{array}$ & $\begin{array}{l}\text { Intervention } \\
\text { IVMP (followed by OPT) daytime }(10: 00-14: 00)(n=N R) \text { vs IVMP } \\
\text { (followed by OPT) nighttime }(22: 00-02: 00)^{\mathrm{a}}(\mathrm{n}=\mathrm{NR}) \\
\text { Treatment duration } \\
\text { IVMP: } 6 \text { days; OPT: NR (reduction every } 2 \text { days) } \\
\text { Assessments } \\
\text { Trial entry, day } 7 \text {, and day } 30 \text { from treatment onset }\end{array}$ & $\begin{array}{l}\text { Mean EDSS (SD) } \\
\text { Baseline: } 6.1 \text { (I.4) in daytime group, } 6.5 \text { (I.4) in } \\
\text { nighttime group } \\
\text { Following treatment: EDSS improvement observed } \\
\text { in both groups (unit change not reported) } \\
\text { Day 7: Nighttime group only attained a reduction of } \\
>2 \text { points in EDSS }\end{array}$ \\
\hline
\end{tabular}

Note: ${ }^{a}$ Patients in one arm presenting successive relapse were treated with the other arm protocol.

Abbreviations: EDSS, Expanded Disability Status Scale; IVMP, intravenous methylprednisolone; OPT, oral prednisone taper; NR, not reported; SD, standard deviation.

Table 7 Intravenous methylprednisolone followed by oral prednisone taper, either alone or concomitant with PMP or IA

\begin{tabular}{|c|c|c|}
\hline $\begin{array}{l}\text { Study/N/Age/ } \\
\text { Location }\end{array}$ & Intervention and treatment duration & Summary of efficacy results \\
\hline $\begin{array}{l}\text { Schmitt et al }(1990)^{33} \\
\mathrm{~N}=17 \\
\text { Age: NR } \\
\text { Germany }\end{array}$ & $\begin{array}{l}\text { Intervention } \\
\text { IVMP vs IVMP and PMP vs IVMP and IAIVMP in each arm followed by OPT); all n= NR } \\
\text { Treatment duration } \\
\text { IVMP: I week } \\
\text { OPT: } 4 \text { weeks } \\
\text { PMP: I week } \\
\text { IA: I week } \\
\text { Assessments } \\
\text { Prior to study entry as well as } 2 \text { weeks, } 3 \text { months, and I year after baseline }\end{array}$ & $\begin{array}{l}\text { EDSS scores }{ }^{\mathrm{a}} \\
\text { IVMP (followed by OPT): } \\
\text { Baseline: } \sim 4.9 \\
2 \text { weeks: } \sim 4.4 \\
3 \text { months: } \sim 5 \\
\text { I year: } \sim 6.2 \\
\text { IVMP (followed by OPT) and PMP: } \\
\text { Baseline: } \sim 5 \\
2 \text { weeks: } \sim 4.2 \\
3 \text { months: } \sim 3.8 \\
\text { I year: } \sim 4.5 \\
\text { IVMP (followed by OPT) and IA: } \\
\text { Baseline: } \sim 5.4 \\
2 \text { weeks: } \sim 3.8 \\
2 \text { months: } \sim 3.3 \\
\text { I year: } \sim 5.3\end{array}$ \\
\hline
\end{tabular}

Note: The dose used in this study was $60 \mathrm{mg} /$ day for one week, followed by $30 \mathrm{mg}$ oral CS for 4 weeks. This is below the accepted dose of $500 \mathrm{mg}$ to I g per day. ${ }^{a}$ Estimated from figure; actual values not reported.

Abbreviations: EDSS, Expanded Disability Status Scale; IA, immunoadsorption; IVMP, intravenous methylprednisolone; NR, not reported; OPT, oral prednisone taper; PMP, plasmapheresis; RCT, randomized controlled trial. 
Table 8 Intravenous methylprednisolone versus oral methylprednisolone

\begin{tabular}{|c|c|c|}
\hline Study/N/Age/Location & $\begin{array}{l}\text { Intervention and treatment } \\
\text { duration }\end{array}$ & Summary of efficacy results \\
\hline $\begin{array}{l}\text { Alam et al }(1993)^{38} \\
\mathrm{~N}=35 \\
\text { Mean age, years: injection, } 41.6 \text {; tablets, } \\
41.3 \\
\text { UK }\end{array}$ & $\begin{array}{l}\text { Intervention } \\
\text { IVMP }(n=20) \text { vs OMP }(n=15) \\
\text { Treatment duration } \\
\text { IVMP and OMP: } 5 \text { days } \\
\text { Assessments } \\
\text { Days } 0,5 \text {, and } 28\end{array}$ & $\begin{array}{l}\text { DSS mean score } \\
\text { Baseline: IVMP, } 4.85 \text {; OMP, } 4.80 \\
\text { Day 5: Results not presented. } \\
\text { Day 28: IVMP, 3.5; OMP, } 3.67 \\
P<0.0 \text { I for both groups vs baseline }\end{array}$ \\
\hline $\begin{array}{l}\text { Barnes et al }(1997){ }^{37} \\
N=80 \\
\text { Mean age, years (SD): IVMP, } 37 \text { (II.I); } \\
\text { OMP, } 38(9.6) \\
\text { UK }\end{array}$ & $\begin{array}{l}\text { Intervention } \\
\text { IVMP }(n=38) \text { vs OMP }(n=42) \\
\text { Treatment duration } \\
\text { IVMP, } 3 \text { days; OMP, } 2 \text { I days } \\
\text { Assessments } \\
\text { Baseline, I week, } 4 \text { weeks, I } 2 \text { weeks, and } \\
24 \text { weeks }\end{array}$ & $\begin{array}{l}\text { EDSS median (IQR) } \\
\text { Baseline: IVMP, } 6.0 \text { (3.5-7.5); OMP: } 5.0(3.5-6.5) \\
\text { Change (improvement) from baseline at: } \\
\text { Week I: IVMP, } 0 \text { (0-0.5); OMP, } 0.5(0-1) \\
\text { Week 4: IVMP, 0.5; OMP, } 0.5 \text { (adjusted mean difference, } \\
-0.0 \text { I7; P=0.80) } \\
\text { Week I2: IVMP, } 0.5 \text { (0-I.5); OMP, } 0.5(0-1.5) \\
\text { Week 24: IVMP, } 0.5 \text { (0-I.5); OMP, } 0.75(0-1.5)\end{array}$ \\
\hline $\begin{array}{l}\text { COPOUSEP Trial }(2015)^{36} \\
\mathrm{~N}=199 \\
\text { Median age, years: oral: } 35.0 ; \text { IV: } 34.7 \\
\text { France }\end{array}$ & $\begin{array}{l}\text { Intervention } \\
\text { IVMP }(n=99) \text { vs OMP }(n=100) \\
\text { Treatment duration } \\
3 \text { days } \\
\text { Assessments } \\
\text { I week, } 4 \text { weeks, and I } 2 \text { weeks }\end{array}$ & $\begin{array}{l}\text { Mean EDSS score improvement from baseline (I week) } \\
4 \text { weeks: } \\
\text { OMP, I.5; IVMP, I.3 (difference, } 0.13 ; P=0.57 \text { ) } \\
\text { I } 2 \text { weeks: } \\
\text { OMP, I.6; IVMP, I.5 (difference, } 0.1 ; P=0.69 \text { ) }\end{array}$ \\
\hline $\begin{array}{l}\text { Martinelli et al }(2009)^{35} \\
\mathrm{~N}=40 \\
\text { Mean age, years: IVMP: } 31.0 \text { (7.0); OMP: } \\
36.0(8.0) \\
\text { Italy }\end{array}$ & $\begin{array}{l}\text { Intervention } \\
\text { IVMP }(n=20) \text { vs OMP }(n=20) \\
\text { Treatment duration } \\
5 \text { days } \\
\text { Assessments } \\
\text { Baseline, weeks I and } 4\end{array}$ & $\begin{array}{l}\text { Improvement ( } \geq \text { I point in EDSS score); } P<0.00 \text { I for both } \\
\text { groups: } \\
\text { Week I: IVMP, } 65 \% \text {; OMP, } 35 \% \\
\text { Week 4: IVMP, } 85 \% \text {; OMP, } 55 \% \\
\text { EDSS did not differ between the } 2 \text { groups at the different } \\
\text { time points }\end{array}$ \\
\hline $\begin{array}{l}\text { Ramo-Tello et al }(2014) ;{ }^{34} \text { Grau-Lopez et } \\
\text { al }(2014)^{39} \\
\mathrm{~N}=49 \\
\text { Mean age, years: IVMP, 37.7; OMP, } 39.5 \\
\text { Spain }\end{array}$ & $\begin{array}{l}\text { Intervention } \\
\text { IVMP }(n=24) \text { vs OMP }(n=25) \\
\text { Treatment duration } \\
3 \text { days } \\
\text { Assessments } \\
\text { Baseline and weeks I, 4, and I2 }\end{array}$ & $\begin{array}{l}\text { Improvement in EDSS scores ( } \geq 1 \text { score change) vs base- } \\
\text { line at } 4 \text { weeks: } \\
\text { IVMP, I.II; OMP, I.I I (mean difference between groups, } \\
0.00 ; P=0.988 \text { ) }\end{array}$ \\
\hline
\end{tabular}

Abbreviations: COPOUSEP, Corticothérapie Orale dans les Poussées de Sclérose en Plaques; DSS, Disability Status Scale; EDSS, Expanded Disability Status Scale; IQR, interquartile range; IV, intravenous; IVMP, intravenous methylprednisolone; NR, not reported; OMP, oral methylprednisolone; SD, standard deviation; UK, United Kingdom.

weeks 4, 12, and 24; OMP did not show a clinically significant improvement over the study period. ${ }^{37}$ The remaining study reported a clinically significant change versus baseline on the DSS scale; however, without a definition of clinically significant change, this result could not be verified. ${ }^{38}$

Intravenous methylprednisolone in combination with erythropoietin versus intravenous methylprednisolone plus placebo One pilot RCT involving 20 patients assessed whether the combination of IVMP and erythropoietin (EPO) acted synergistically during MS relapse (Table 9). ${ }^{40}$ The study was based on evidence of the neuroprotective properties of
EPO from in vitro and in vivo studies of brain diseases. Definitions of relapse and clinically significant improvement in EDSS were not reported. When the standard definition of clinically significant change was applied (a gain of $\geq 0.5$ point on the EDSS in patients with baseline EDSS of $>5.5^{22}$ ), improvement in mean EDSS scores versus baseline was first observed with IVMP and placebo at 1 month and continued to increase at months 2 and 3.

\section{Intravenous immunoglobulin}

Two studies assessed the efficacy of IVIG (Table 10). ${ }^{41}$ Because IVIG was combined with IVMP in both studies, 
Table 9 Intravenous methylprednisolone vs intravenous methylprednisolone plus erythropoietin

\begin{tabular}{|c|c|c|}
\hline Study/N/Age/Location & Intervention and treatment duration & $\begin{array}{l}\text { Summary of efficacy } \\
\text { results }\end{array}$ \\
\hline $\begin{array}{l}\text { Najmi Varzaneh et al }(20 \mid 4)^{40} \\
\mathrm{~N}=20 \\
\text { Mean age, years: not treated: } 29.7 \text { (SD, 2.9); treated: } \\
30.5 \text { (SD, 2.7I) } \\
\text { Iran }\end{array}$ & $\begin{array}{l}\text { Intervention } \\
\text { IVMP and IV EPO simultaneously }(n=10) \text { vs IVMP and placebo } \\
\text { simultaneously }(n=10) \\
\text { Treatment duration } \\
5 \text { days } \\
\text { Assessments } \\
5 \text { days after treatment onset and at the end of months I, } 2 \text {, and } 3\end{array}$ & $\begin{array}{l}\text { Mean EDSS } \\
\text { IVMP and EPO: } \\
\text { Baseline, } 6.60 \\
\text { Month I, } 5.30 \\
\text { Month 2, } 3.00 \\
\text { Month 3, I.40 } \\
\text { IVMP and placebo: } \\
\text { Baseline, } 6.60 \\
\text { Month I, } 5.30 \\
\text { Month 2, } 4.50 \\
\text { Month 3, } 3.90\end{array}$ \\
\hline
\end{tabular}

Abbreviations: EDSS, Expanded Disability Status Scale; EPO, erythropoietin; IV, intravenous; IVMP, intravenous methylprednisolone; NR, not reported; RCT, randomized controlled trial.

Table 10 Intravenous immunoglobulin and intravenous methylprednisolone

\begin{tabular}{|c|c|c|}
\hline Study/N/Age/Location & Intervention and treatment duration & Summary of efficacy results \\
\hline $\begin{array}{l}\text { TARIMS Study }(2004)^{4 I} \\
\text { N=76 } \\
\text { Mean age, years: IVIG, } \\
\text { 35.3; placebo, } 35.2 \\
(P=0.99) \\
\text { Germany, Denmark, } \\
\text { Sweden }\end{array}$ & $\begin{array}{l}\text { Intervention } \\
\text { IVIG followed by IVMP } 24 \text { hrs later }(n=36) \\
\text { vs placebo followed by IVMP } 24 \text { hrs later } \\
(n=40) \\
\text { Treatment duration } \\
\text { NR } \\
\text { Assessments } \\
\text { Baseline, } 4 \text { days after treatment onset, and } \\
3,12 \text {, and } 26 \text { weeks after treatment onset }\end{array}$ & $\begin{array}{l}\text { Baseline EDSS: } \\
\text { IVIG followed by IVMP: } 4.4 \pm \text { I.3; placebo followed by IVMP: } 4.2 \pm 1.3 \\
\text { Improvement from baseline in EDSS scores: } \\
\text { Day 4: IVIG followed by IVMP, } 0.63 \text {; placebo followed by IVMP, } 0.69 \\
\text { Week 3: IVIG followed by IVMP, I.28; placebo followed by IVMP, } 0.96\end{array}$ \\
\hline $\begin{array}{l}\text { Visser et al }(2004)^{42} \\
N=19 \\
\text { Mean age, years: IVMP } \\
\text { followed by IVIG, } 37.5 \text {; } \\
\text { IVMP, } 38 . \text { I } \\
\text { The Netherlands }\end{array}$ & $\begin{array}{l}\text { Intervention } \\
\text { IVMP followed by IVIG }(n=10) \text { vs IVMP fol- } \\
\text { lowed by placebo }(n=9) \\
\text { Treatment duration } \\
5 \text { days } \\
\text { Assessments } \\
\text { Upon entry, after I, } 2,4,8 \text {, and } 12 \text { weeks, } \\
\text { after } 6 \text { months, and during relapse } \\
\text { occurrence }\end{array}$ & $\begin{array}{l}\text { Baseline median (range) EDSS: } \\
\text { IVMP followed by IVIG, } 3.75 \text { ( } 3-6.5) \text {; IVMP followed by placebo, } 3.5 \text { ( } 2 \text {, } \\
5-7 \text { ) } \\
\text { Median change in EDSS from baseline to: } \\
\text { Week I: not reported } \\
\text { Week 2: not reported } \\
\text { Week 4: IVMP followed by IVIG, I.0 }(95 \% \mathrm{Cl}, 0-3) \text {; IVMP followed by } \\
\text { placebo, I.0 ( } 95 \% \mathrm{Cl}, 0.28-I .94) ; P=0.8 \mathrm{I} \\
\text { Percentage of patients achieving a I-point EDSS score improvement at } \\
\text { week 4: IVMP followed by IVIG, } 60 \% \text {; IVMP followed by placebo, } 67 \% \text {; } \\
P=0.76\end{array}$ \\
\hline
\end{tabular}

Abbreviations: AE, adverse event; EDSS, Expanded Disability Status Scale; IVIG, intravenous immunoglobulin; IVMP, intravenous methylprednisolone; NR, not reported.

conclusions regarding the efficacy of IVIG alone cannot be made.

Efficacy insights were then sought by looking across treatment groups. One study showed clinical improvement with IVIG followed by IVMP therapy at week 3, which was slightly improved compared with the improvement seen with IVMP only. ${ }^{41}$ The other study showed equivalent clinical improvement from baseline to week 4, with both IVMP followed by IVIG and IVMP only. ${ }^{42}$
The first study evaluated IVIG versus placebo, both followed by IVMP $24 \mathrm{hrs}$ later, in 76 patients. Acute relapse was defined as the development of new or worsening of existing neurologic symptoms or signs in the absence of fever persisting for more than $24 \mathrm{hrs}$ and with a previous period of more than 30 days with a stable or improving condition. ${ }^{41}$ A definition of clinically significant change in EDSS was not presented in the study, and the standard definition could not be applied ( $\geq 1$ EDSS 
score change in patients with EDSS $\leq 5.5$ or a gain of $\geq 0.5$ point EDSS in patients with baseline EDSS of >5.5) because baseline EDSS scores spanned across the 5.5 EDSS threshold. ${ }^{22}$ However, at week 3, patients receiving combination therapy with IVIG showed an improvement of 1.28 units EDSS, which meets the standard definition of clinically significant change regardless of patients' baseline EDSS. ${ }^{41}$ Numerical improvements in EDSS scores versus baseline were seen in both treatment groups at day 4. Across treatment groups, EDSS improvements were small and inconsistently greater for those receiving IVIG + IVMP versus those receiving IVMP only.

The second study evaluated IVMP followed by IVIG versus IVMP followed by placebo in 19 patients; it was unclear when the second therapy followed within the treatment timeline. Relapse was defined as a $\geq 1$-point increase in EDSS score (compared with pre-attack EDSS score) and <22-day duration. ${ }^{42}$ The study demonstrated that most patients achieved a 1-point EDSS score improvement. ${ }^{42}$ When comparing treatment groups, a smaller percentage of patients receiving IVMP followed by IVIG showed significant improvement at 4 weeks versus baseline, compared with IVMP alone $(60 \%$ vs $67 \%$, respectively; $P=0.76$ ). However, both arms had a significant median EDSS improvement at week 4 versus baseline $(P=0.81)$.

\section{Plasmapheresis}

Two studies assessing PMP were identified in which PMP was given in combination with other therapy; the efficacy of PMP alone could not be directly assessed from these studies because PMP was used in combination with other therapies.

Efficacy insights were then sought across treatment groups. One study showed increased clinical improvement in EDSS with the addition of PMP at 3 months, which was not seen in the control arm. ${ }^{33}$ Another study showed clinical improvement at all study timepoints (Table 11). ${ }^{43,44}$

One study assessed PMP and IVMP followed by OPT in a small sample of 17 patients (and is also presented in Section 3.2.1.5). A definition of clinically significant EDSS change was not presented; however, the standard definition of $\geq 1$ EDSS score change in patients with baseline EDSS score $\leq 5.5^{22}$ could be applied. According to this, clinically nonsignificant improvements in EDSS scores were seen at week 2 versus baseline. Looking across groups, the addition of PMP to combination therapy showed increased EDSS change versus baseline compared with the group not receiving PMP; however, this was not clinically significant at 2 weeks. At 3 months, clinical improvement was observed in the group receiving PMP compared with the group not receiving PMP. ${ }^{33}$

The Cooperative Study of PMP, conducted in a US cohort of 116 patients, compared an 8-week course of PMP with placebo (each with RCI plus cyclophosphamide) in the treatment of MS relapses; therefore, the efficacy of PMP alone could not be assessed in this study (Table 11). ${ }^{43,44}$ Relapse was defined as an episode of worsening characterized by a decline of at least 1 grade on the Kurtzke DSS that was present for $>5$ days but no longer than 8 weeks without evidence of improvement from the inception of the worsening. A reduction of 1 grade in DSS was defined as improvement in patients entering the study with a grade of $\geq 6 \mathrm{~B}$. For patients with a grade of $\leq 6 \mathrm{~A}$, a reduction of 2 grades was required. Patients receiving PMP showed improvement in DSS scores at 2 weeks versus baseline; the extent of improvement subsequently declined over the next assessment timepoints. Compared with patients not receiving PMP, DSS improvement was higher over all time points evaluated. The results suggested that PMP given with RCI plus cyclophosphamide enhanced recovery from an acute MS relapse compared with the control arm (placebo given with RCI plus cyclophosphamide). ${ }^{43,44}$

\section{Repository corticotropin injection}

Two RCTs evaluated treatment with RCI (Table 12). In one study, the proportion of patients with improved DSS score was higher with intramuscular RCI than with placebo, at week 1, 2, 3, and 4. In the other study, mean EDSS score with IM RCI were improved compared with subcutaneous RCI at days 7 and 14 ( \pm 1 day).

The National Cooperative Clinical Trial ${ }^{45-47}$ assessed therapeutic response to a 2-week course of RCI IM (vs placebo) in treating 197 relapse-remitting patients with acute MS relapses; no relapse definition was provided. In the RCI group, a consistently larger proportion of patients showed improvement ( $\geq 1$-unit change DSS) at 1,2,3, and 4 weeks after initiation of treatment with RCI versus placebo (RCI: $38 \%, 57 \%, 61 \%$, and $65 \%$; placebo: $26 \%$, $38 \%, 49 \%$, and $48 \%$, respectively).

A 2-week, prospective, randomized, open-label, singlecenter, pilot study by Simsarian, Saunders, $\mathrm{Smith}^{48}$ compared a short (5-day) self-administered course of IM versus SC RCI in a small sample of patients $(n=20)$, from baseline. ${ }^{48}$ On days 7 and 14, following the initiation of treatment, the 
Table I I Plasmapheresis versus placebo

\begin{tabular}{|c|c|c|}
\hline Study/N/Age/Location & Intervention and treatment duration & Summary of efficacy results \\
\hline $\begin{array}{l}\text { Schmitt et al }(1990)^{33} \\
\mathrm{~N}=17 \\
\text { Age: NR } \\
\text { Germany }\end{array}$ & $\begin{array}{l}\text { Intervention } \\
\text { IVMP vs IVMP and PMP vs IVMP and IA (IVMP in each arm } \\
\text { followed by OPT); all n= NR } \\
\text { Treatment duration } \\
\text { IVMP: I week } \\
\text { OPT: } 4 \text { weeks } \\
\text { PMP: I week } \\
\text { IA: I week } \\
\text { Assessments } \\
\text { Prior to study entry as well as } 2 \text { weeks, } 3 \text { months, and I year } \\
\text { after baseline }\end{array}$ & $\begin{array}{l}\text { EDSS scores }{ }^{\mathrm{a}} \\
\text { IVMP (followed by OPT) and PMP: } \\
\text { Baseline: } 5 \\
2 \text { weeks: } 4.2 \\
3 \text { months: } 3.8 \\
\text { I year: } 4.5 \\
\text { IVMP (followed by OPT): } \\
\text { Baseline: } 4.9 \\
2 \text { weeks: } 4.4 \\
3 \text { months: } 5 \\
\text { I year: } 6.2 \\
\text { IVMP (followed by OPT) and IA: } \\
\text { Baseline: } 5.4 \\
2 \text { weeks: } 3.8 \\
2 \text { months: } 3.3 \\
\text { I year: } 5.3\end{array}$ \\
\hline $\begin{array}{l}\text { Cooperative Study of PMP (1989, } \\
\text { 1990) } \\
\mathrm{N}=116 \\
\text { Mean (SD) age at treatment, years: } \\
\text { RRMS PMP: } 32.7 \text { (SD, 6.I) } \\
\text { RRMS placebo: } 32.1 \text { (SD, 7.5) } \\
\text { US }\end{array}$ & $\begin{array}{l}\text { Intervention } \\
\text { PMP with } \mathrm{RCl} \text { plus oral CFX within } 24 \text { hrs of PMP }(n=5,959) \text { vs } \\
\text { placebo }{ }^{\text {b }} \text { with } \mathrm{RCl} \text { plus oral CFX within } 24 \text { hrs of placebo } \\
(\mathrm{n}=5,757) \\
\text { Treatment duration } \\
\text { PMP: } 5 \text { times in first I } 4 \text { days, then weekly for } 6 \text { weeks } \\
\text { ACTH: twice daily for II days, then once daily for } 3 \text { days } \\
\text { CFX: Daily for } 12 \text { weeks } \\
\text { Assessments } \\
\text { Prior to treatment and } 2 \text { weeks as well as I, } 2,3,6,18 \text {, and } \\
24 \text { months after treatment onset }\end{array}$ & 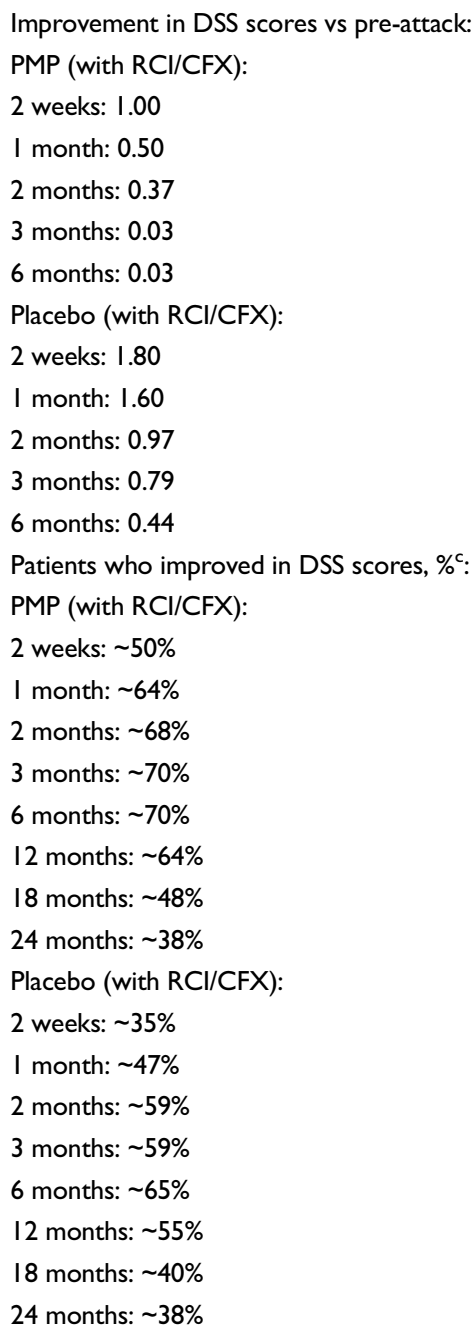 \\
\hline
\end{tabular}

Notes: PMP: $60 \mathrm{~mL} / \mathrm{kg}$ body weight of patient plasma was exchanged for $3.5 \%$ albumin in normal saline containing $6.9 \mathrm{mEq} \mathrm{Ca}^{2+} / \mathrm{L}, 2 \mathrm{mEq} \mathrm{mg}^{2+} / \mathrm{L}$, and $4 \mathrm{mEq} \mathrm{K} / \mathrm{L}$. ${ }^{\mathrm{P}}$ Patients in one arm presenting successive relapse were treated with the other arm protocol. ${ }^{b}$ Control subjects received an identical regimen of a timed placebo procedure during which their plasma was continuously separated, recombined with their blood cells, and returned to them. ${ }^{\circ}$ Estimated from figure; actual values not reported.

Abbreviations: CFX, cyclophosphamide; DSS, Disability Status Scale; PMP, plasmapheresis; RCl, repository corticotropin injection; RCT, randomized controlled trial; RRMS, relapse-remitting multiple sclerosis; SD, standard deviation; US, United States. 
Table 12 Repository corticotropin injection

\begin{tabular}{|c|c|c|}
\hline Study/N/Age/Location & Intervention and treatment duration & Summary of efficacy results \\
\hline $\begin{array}{l}\text { National Cooperative Clinical } \\
\text { Trial } \\
\text { Henderson et al }(1978)^{45} \\
\text { Rose et al }(1969)^{46} \\
\text { Rose et al }(1970)^{47} \\
N=197 \\
\text { Age: NR } \\
\text { US }\end{array}$ & $\begin{array}{l}\text { Intervention } \\
\mathrm{RCI} I M(n=103) \text { vs placebo }(\mathrm{n}=94) \\
\text { Treatment duration } \\
\text { I4 days } \\
\text { Assessments } \\
\text { Within } 24 \text { hrs of treatment onset, days } 7 \text { and I } 4 \text { of } \\
\text { treatment, and days } 7 \text { and } 14 \text { following treatment }\end{array}$ & $\begin{array}{l}\text { Proportion of patients improved DSS score ( } \geq \text { I score } \\
\text { change) at week I after treatment initiation: } \\
\mathrm{RCl}, 38 \% \text {; placebo, } 26 \% \\
\text { DSS at week 2: } \mathrm{RCl}, 57 \% \text {; placebo, } 38 \% \\
\text { DSS at week 3: } \mathrm{RCl}, 61 \% \text {; placebo, } 49 \% \\
\text { DSS at week 4: } \mathrm{RCl}, 65 \% \text {; placebo, } 48 \%\end{array}$ \\
\hline $\begin{array}{l}\text { Simsarian et al }(201 \mathrm{I})^{48} \\
\mathrm{~N}=20 \\
\text { Age: } 39.5 \\
\text { US }\end{array}$ & $\begin{array}{l}\text { Intervention } \\
\mathrm{RCI} S C(\mathrm{n}=10) \text { vs } \mathrm{RCI} I M \text { (both self-administered) } \\
(\mathrm{n}=10) \\
\text { Treatment duration } \\
5 \text { days } \\
\text { Assessments } \\
\text { Baseline, days } 7 \text { and } 14\end{array}$ & $\begin{array}{l}\text { Mean EDSS scores at baseline: IM, 2.30; SC, } 2.80 \text {; all, } \\
2.55 \\
\text { Mean EDSS score on day } 7 \pm I \text { day: IM, I.20; SC, } 2.65 \text {; } \\
\text { all, I.93 } \\
\text { Mean EDSS scores on day I4 } 4 \text { I day: IM, I. I0; SC, } \\
2.89 \text {; all, I.95 }\end{array}$ \\
\hline
\end{tabular}

Abbreviations: DSS, Disability Status Scale; EDSS, Expanded Disability Status Scale; IM, intramuscular; NR, not reported; RCI, repository corticotropin injection; RCT, randomized controlled trial; SC, subcutaneous; US, United States.

mean EDSS score reduction for IM was above the generally accepted threshold of clinical improvement ${ }^{22}$ (EDSS, 1.1 and 1.2 , respectively). However, the SC cohort failed to show clinical improvement, as did the combined SC and IM group (Table 12). The authors noted that the baseline mean EDSS score of 2.55 signaled high initial functioning, indicating mild to moderate disability at study entry. ${ }^{48}$ Further, only 10 patients were studied in each arm.

An additional study of PMP with RCI plus oral cyclophosphamide within $24 \mathrm{hrs}$ of first PMP or placebo is presented in Section 3.2.3, demonstrating that this regimen enhanced recovery from an acute MS relapse. ${ }^{43,44}$ However, results for RCI alone are not available in this study and cannot be assessed compared with other treatment arms due to the study design.

\section{Quality-of-life outcomes}

Three RCTs reported data for IVMP. Two of the three studies had small sample sizes. Only one study provided a definition of clinically significant change (ie $\geq 10$ points, for the SF-36, as established via a pilot study and analysis of previously published data); ${ }^{49}$ no definitions were provided in the other two studies and standard definitions of clinically significant change could not be identified in the literature. Authors' interpretations were presented in these cases (Table 13).

Chataway, Porter, Riazi, Heaney, Watt, Hobart, Thompson $^{31}$ assessed QOL changes in patients receiving IVMP administered in an outpatient versus home setting using the SF-36. Both treatment groups experienced some improvements; all domains of SF-36 improved after 6 weeks of treatment in an outpatient setting, and 7 of the 8 domains improved with treatment at home.

Craig, Young, Ennis, Baker, Boggild ${ }^{49}$ assessed QOL changes at 1 month relative to baseline in patients receiving IVMP with planned, comprehensive multidisciplinary team care versus standard care using the SF-36. Multidisciplinary care included advice for continuing self-management and referral to other agencies after discharge if appropriate. Treatment was nonstandard, as symptom presentation varied, and therapy was focused on meeting subjects' needs at the time. SF-36 mean score improvements were of greater magnitude in the treatment group than in the control group and were seen across a higher number of SF-36 domains. At 1 month, clinically significant score changes $(\geq 10$ units) were seen in both groups for Physical Function, Social Function, Role Emotional, Mental Health, and Pain. In the treatment group only, changes were also seen in Role Physical, Energy, and General Health. At 3 months, clinically significant score changes were seen in both groups for Social Function and Role Physical domains. In the treatment group only, changes were also seen in the Physical Function, Mental Health, Energy, and Pain domains.

In the study reported by Ramo-Tello, Grau-Lopez, Tintore, Rovira, Ramio i Torrenta, Brieva, Cano, Carmona, Saiz, Torres, Giner, Nos, Massuet, Montalban, Martinez- 


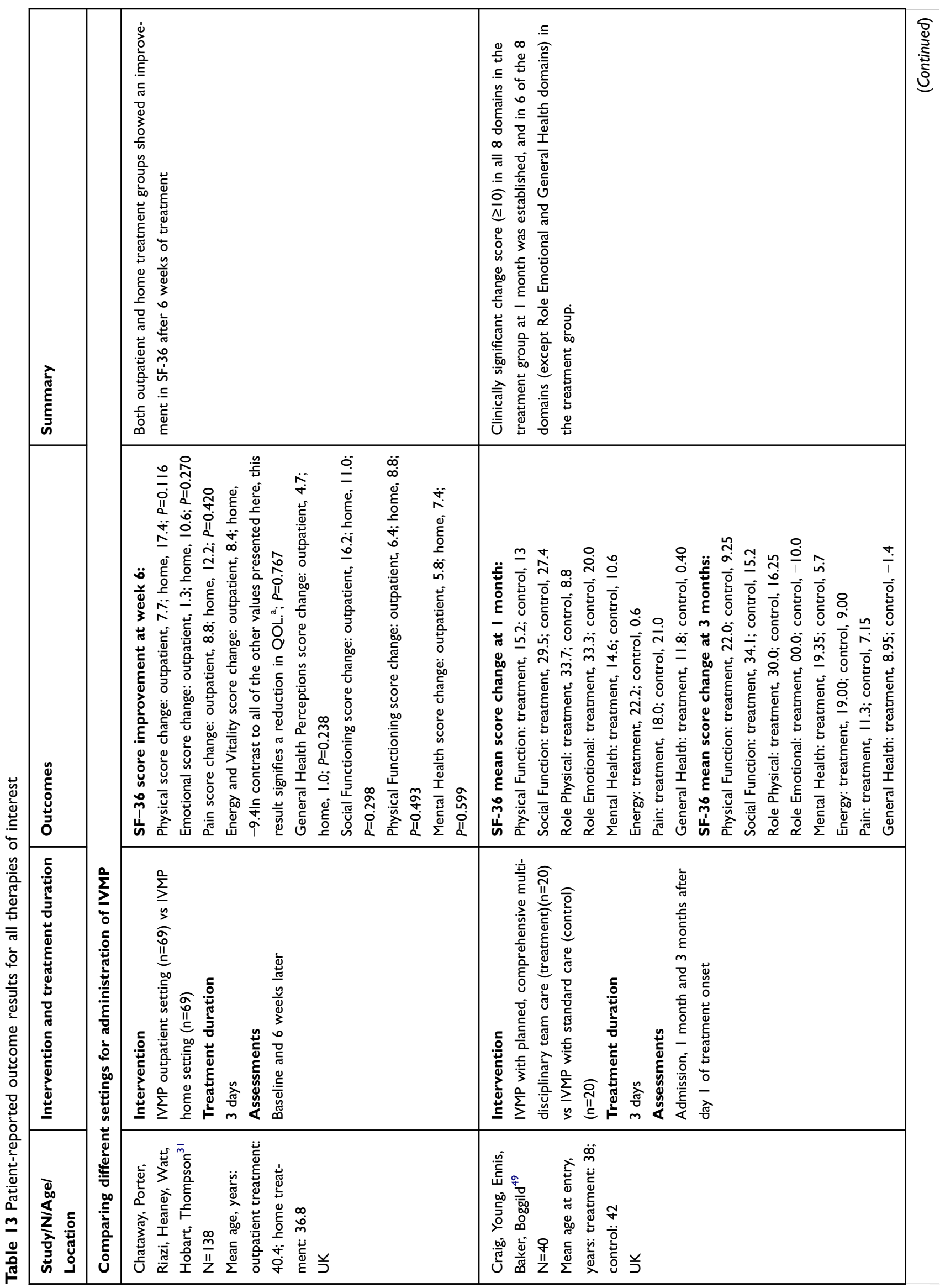




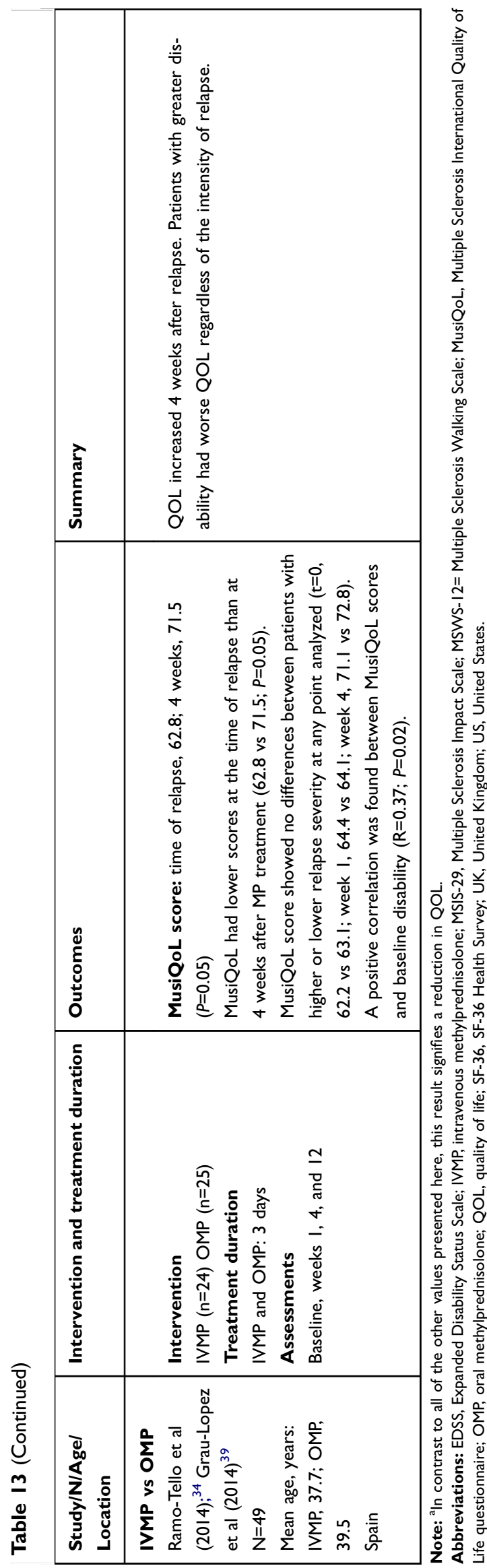

Caceres, Costa ${ }^{34}$ and Grau-Lopez, Tintore, Ramio-Torrenta, Brieva, Saiz, Nos, Cano, Carmona, Hervas, Montalban ${ }^{39}$ comparing IVMP and OMP, Multiple Sclerosis International Quality of Life questionnaire (MusiQoL) scores were lower at the time of relapse than at 4 weeks after methylprednisolone treatment ( 62.8 vs $71.5 ; P=0.05$ ), indicating an improvement with treatment.

\section{Safety outcomes}

Safety data were reported in 12 studies, 8 of which pertained to IVMP only, 2 to RCI and 2 to IVIg. The Schmitt et al study of IVMP (followed by OPT) ${ }^{33}$ did not provide safety data for the treatments of interest and is therefore not included in Table 14. Three of the 8 IVMP studies assessed small samples of patients; the remaining 5 studies reflected sample sizes ranging from 31 to 199 patients. These 8 studies indicated IVMP was generally well tolerated, with nonserious adverse events reported. RCI had 2 RCTs with safety data, one of which had small sample size (Table 14). No SAEs were seen with RCI, and the most common AE observed was acne. No safety data were available PMP.

In the study by Oliveri, Valentino, Russo, Sibilia, Aguglia, Bono, Fera, Gambardella, Zappia, Pardatscher, Quattrone $^{28}$ comparing different doses of IVMP, no major adverse events (AEs) were reported in either group ( $2 \mathrm{~g} /$ day and $0.5 \mathrm{~g} /$ day); minor side effects included insomnia, anxiety symptoms, dyspepsia, ankle edema, and a metallic taste in the mouth. In the study of IVMP (followed by OPT) by Glass-Marmor, Paperna, Ben-Yosef, Miller, ${ }^{32}$ the most commonly reported AEs were frequent urination, metallic taste, restlessness/nervousness, and insomnia. More patients experienced AEs in the daytime group. ${ }^{32}$ In the studies assessing IVMP versus OMP, IVMP was well tolerated, and the most commonly reported AEs included insomnia, headache, and metallic taste. ${ }^{34-36,39}$ In patients with IVMP and EPO versus IVMP and placebo, IVMP treatment was well tolerated. ${ }^{40}$

No AEs were observed in patients treated with PMP and IVMP, or with IVMP alone; AEs were reported in patients treated with IA and IVMP. ${ }^{33}$ Given the sample size of $\mathrm{N}=17$ patients and the preliminary report, results should be interpreted with caution.

The overall incidence of AEs was found to be similar in patients treated with IVIG followed by IVMP and IVMP alone; $72 \%$ patients with IVIG followed by IVMP experienced at least one $\mathrm{AE}$, versus $75 \%$ patients with IVMP alone. ${ }^{41}$ However, as this was a pilot study of 17 


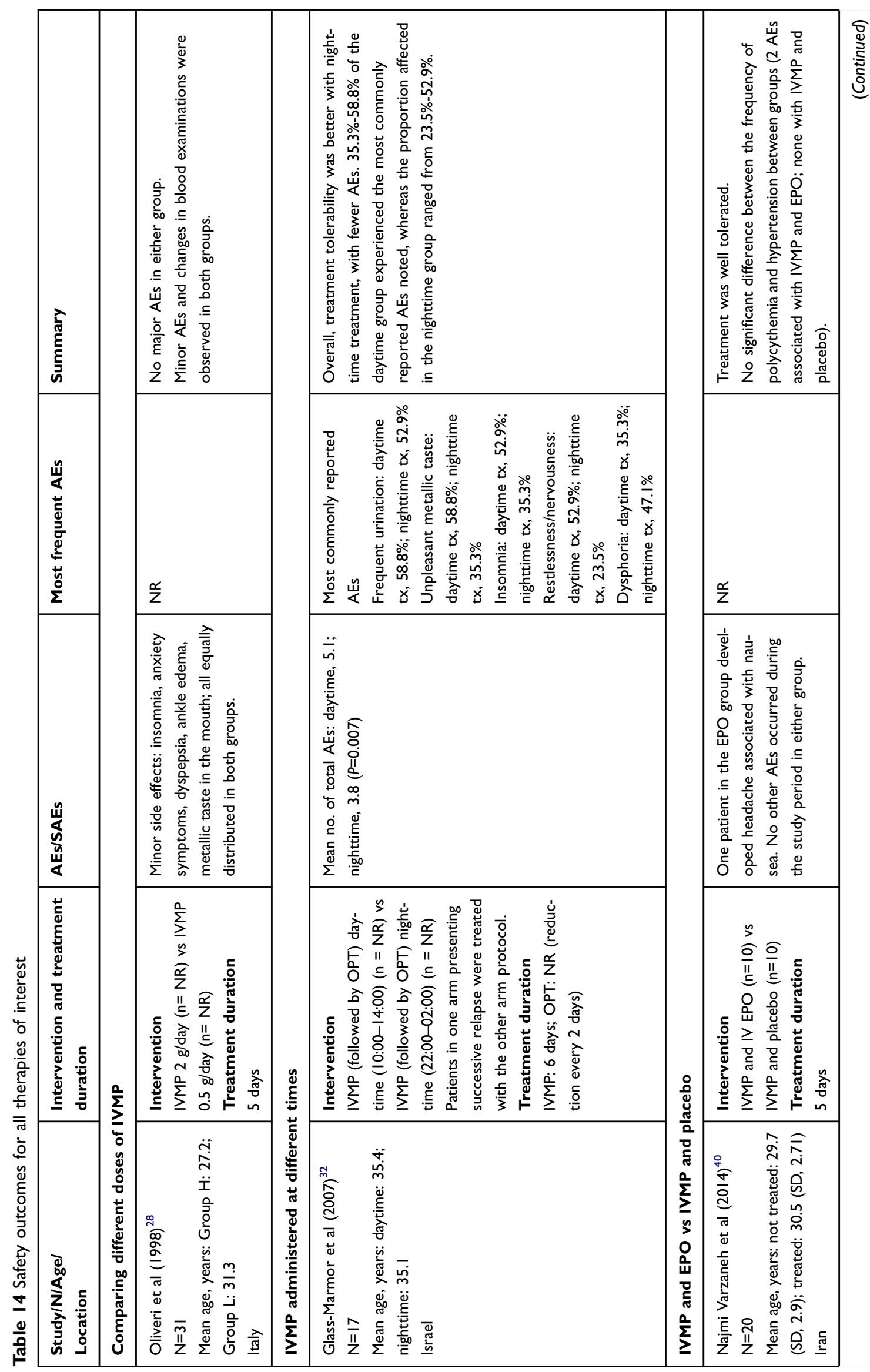




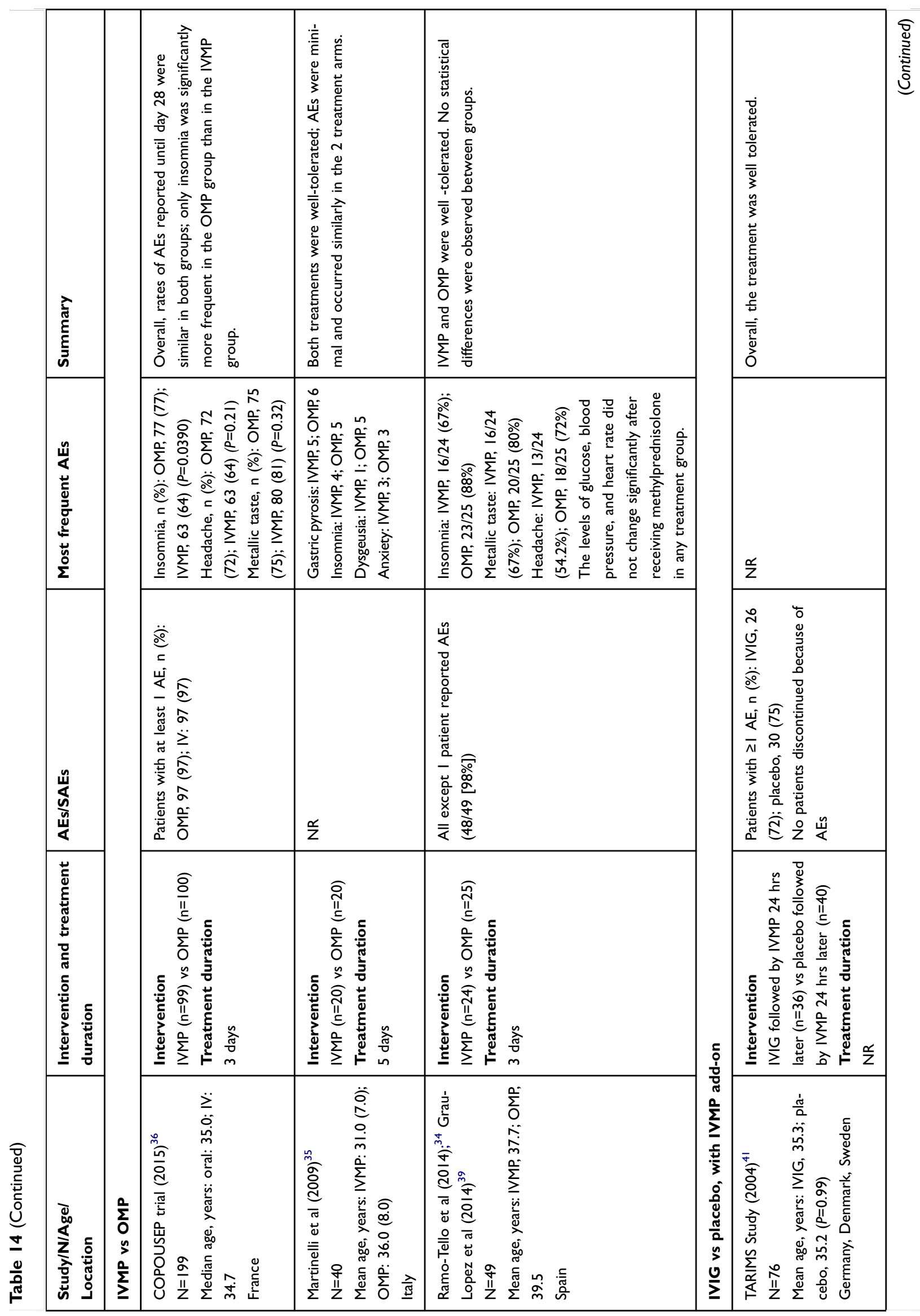




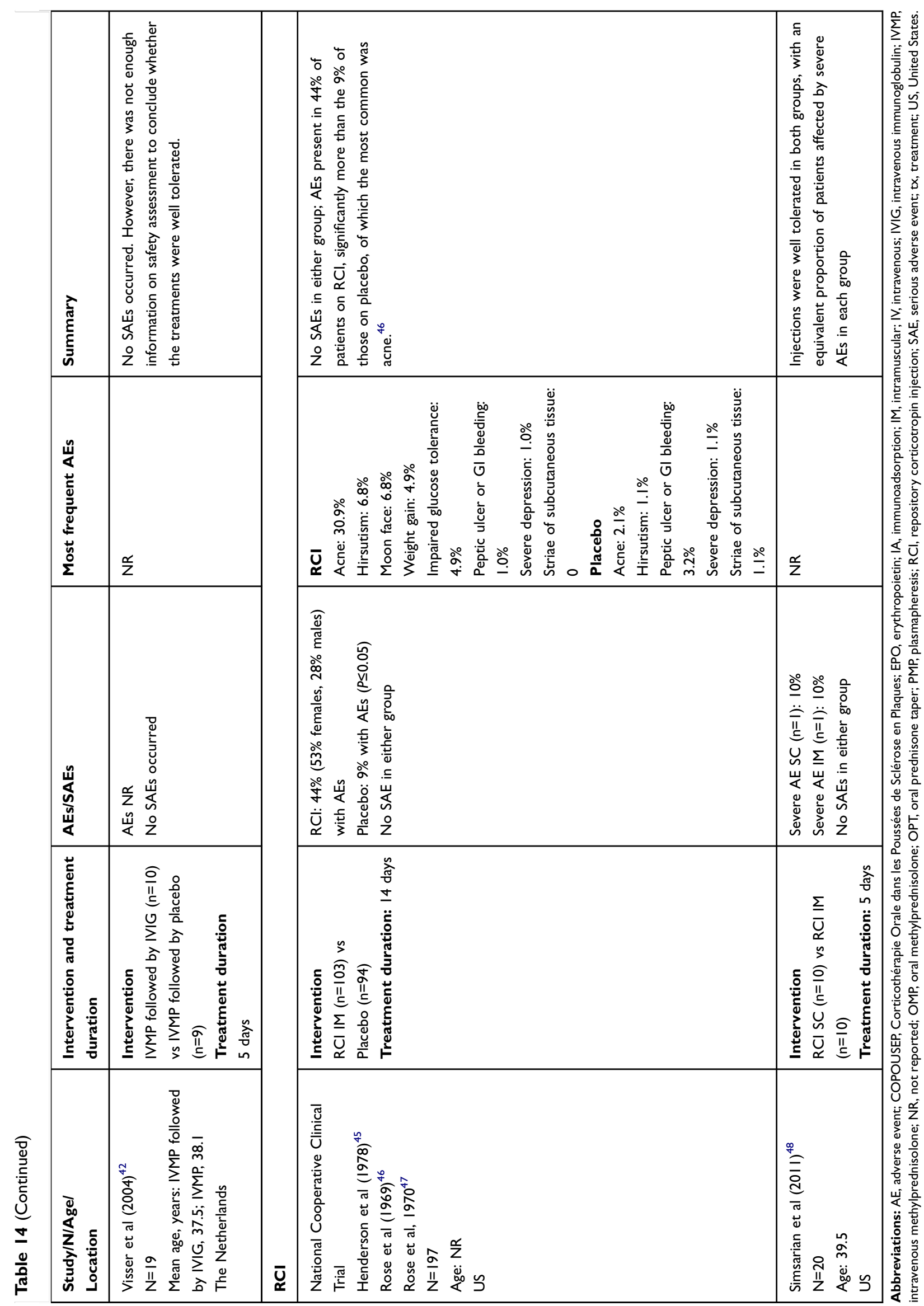


patients, results should be interpreted with caution. In another study of 19 patients, no serious AEs (SAEs) occurred in patients treated with IVIG followed by IVMP and IVMP alone. However, there was not enough information on safety assessment to conclude whether the treatments were well tolerated. ${ }^{42}$

In the pilot study comparing a short (5-day) course of IM versus SC RCI, injections were well-tolerated by both groups; severe AEs were limited and no SAEs were reported. $^{48}$ In the study assessing RCI versus placebo, no SAEs were reported in either group; $44 \%$ of patients receiving $\mathrm{RCI}$ and $9 \%$ of those receiving placebo had AEs, of which the most common was acne. ${ }^{46}$ Incidence of acne and other AEs associated with treatment were not reported. Overall, safety assessments were limited; furthermore, differences in dosage regimens further precluded any robust conclusions.

\section{Discussion}

The aim of this SLR was to identify and assess RCT data for therapies used in the treatment of acute MS relapse: IVMP, RCI, IVIG, and PMP.

EDSS/DSS score was used as a measure of efficacy in most of the studies presented here. Whereas a clear recommendation on how to interpret change in EDSS values is not available in the literature, ${ }^{50}$ a progression of 1.0 or a continuing progression by 1 unit on the scale for at least 6 or 12 months has been recommended by many authors as a clinically significant change; for patients with an EDSS of 5.5 or higher, progression by 0.5 is often deemed sufficient. $^{22,50}$ When a definition of improvement was unspecified, this definition continued to be applied. Baseline EDSS scores were not presented in all studies, and significance could therefore not be determined. In these cases, the authors' conclusions were presented, with the caveat that a definition of clinically significant change was not specified. The vast majority of studies found were dated, with no clear definition for relapse presented and small sample sizes.

IVMP is the recommended first-line treatment for patients with acute MS relapses ${ }^{13}$ prior to other treatments of interest in this SLR [ie, RCI, IVIG, and PMP]). Results reported in this manuscript show that patients treated with IVMP often showed clinically significant improvements in EDSS/DSS scores compared with baseline. ${ }^{23-26,34-38,51}$

Of note, the IVMP regimens, dosages, and treatment durations used in the included studies varied widely, from as low as $0.5 \mathrm{~g} /$ day to $2 \mathrm{~g} / \mathrm{day}$, from 3-15 days, with or without an OPT. Real-world treatment confirms such variation in the dosing and duration of IVMP. In terms of safety, the studies showed that IVMP was generally well tolerated, with some nonserious adverse events reported. Common AEs associated with IVMP include insomnia, headache, and metallic taste.

The gel formulation of ACTH is approved by the FDA for several different indications, given either intramuscularly or subcutaneously. There are limited data available on the duration, dosing, and route of administration of ACTH gel in the treatment of acute exacerbations of multiple sclerosis. $^{48}$ Data from a large US RCT suggested the efficacy of RCI gel administered IM over 15 days increased versus baseline (as measured by proportion of patients improved in DSS scores). ${ }^{45-47}$ Results from a pilot RCT of 20 patients conducted in the US suggested that a shorter 5-day course of self-administered RCI given either IM or SC resulted in improvement in EDSS scores versus baseline. ${ }^{48}$ Occurrence of severe AEs in the RCI studies was limited, and no SAE occurred. The most common AE was acne; however, incidence of this or other common AEs was not reported. ${ }^{47}$ None of the RCI studies reported QOL information.

IVIG could not be assessed as monotherapy versus baseline for acute MS relapse. Notably, two RCTs identified investigated the efficacy of IVIG as an add-on to IVMP in treating MS relapses. ${ }^{41,42}$ In evaluating efficacy observed between treatment groups (Table 11), limited differences were seen in EDSS scores following treatment. Data on AEs showed that IVIG was well tolerated. ${ }^{41}$ No QOL data were available for IVIG.

PMP also could not be assessed as monotherapy. Efficacy was indirectly measured by observation across treatment groups; PMP was given with RCI/cyclophosphamide (CFX) in one study ${ }^{43,44}$ and with IVMP followed by OPT in another. ${ }^{33}$ PMP given with RCI plus CFX enhanced recovery from an acute MS relapse compared with the control arm (placebo given with RCI plus CFX). The addition of PMP to IVMP followed by OPT showed clinical improvement at 3 months, but this was not significant at 2 weeks. ${ }^{33}$

Given the larger evidence base and lower cost of corticosteroids, IVMP has a place as first-line treatment of acute MS relapses in eligible patients. For those patients who do not respond or cannot or should not receive firstline treatment with IVMP, alternative treatments are required. Compared with PMP and IVIG, RCI is the next line of treatment with RCT data supporting its individual 
efficacy and safety as a monotherapy for acute MS relapse. Data for PMP and IVIG are limited to studies in which these treatments are combined with other therapies.

Recent research supports a different mechanism of action for RCI as compared with IVMP. It has been shown that the efficacy of RCI in immune-mediated diseases may not be solely due to steroid production; administration of RCI was shown to result in a significantly lower overall serum cortisol-equivalent exposure versus IVMP. ${ }^{52}$ Nonclinical evidence suggests a potential role for melanocortin peptides, including $\mathrm{ACTH}$, on inflammation and the immune response in both the peripheral and central nervous system that may be independent of endogenous cortisol production. ${ }^{53}$ Considering this evidence, RCI may be appropriate for consideration in patients for whom IVMP is not appropriate given a unique mechanism of action. Recent studies have aimed to characterize patients eligible for RCI. Patients receiving RCI tend to be older, have had MS for a longer duration, and have more functional and neurological impairments, despite use of disease-modifying therapies. Thus, results support the efficacy and tolerability of RCI as a treatment for MS relapse. ${ }^{54}$

\section{Study limitations}

In this report, we present results from RCTs only, which lack generalizability for application in the real-world setting. Treatments of interest not studied in RCTs may have been underrepresented.

Differences were seen in outcomes reported, assessment time points, heterogeneity in patient populations, geographies, and treatment regimens (eg, dose and duration) assessed, between studies conducted in the US versus in countries other than the US, as well as within the US. It was therefore difficult to compare results across studies or summarize results descriptively, and generalizability may have been impacted. Considering studies for IVMP were exclusively conducted in countries other than the US, applicability to the US setting may be particularly problematic in this case. Further, many studies $(n=10)$ included in this SLR had sample sizes of fewer than 30 patients, which may also impact generalizability of results.

We focused on the EDSS in this SLR, a standardized assessment of efficacy in MS relapses, as it was used across the studies identified. However, limitations do exist in the way it is used in different studies. ${ }^{55}$ In the context of evaluating recovery from relapse, establishing a baseline prior to relapse is necessary for later determination of the extent of recovery; it is not sufficient to simply calculate the change in EDSS score from the assessment during the relapse to the assessment after the relapse. Further, it is important to provide a definition for clinical significance of EDSS score change, which was absent in numerous studies. We aimed to mitigate this limitation when possible by applying a standard definition of EDSS clinical significance; however, this definition is dependent on the availability of baseline results and could therefore not always be applied. In these cases, authors' interpretations were used. Differences in the timing of post-relapse follow-up assessments can affect the degree of symptom improvement or residual disability observed. Finally, some evidence suggests that a lack of agreement exists between EDSS scores and patients' perception. ${ }^{55}$

Efficacy results versus baseline were not available for IVIG or PMP alone, as these were combined with other treatments in the studies identified in this SLR. In these cases, cross-arm comparisons were used to determine efficacy.

A further limitation consists of the definition of acute relapses in the studies. Many studies presented here did not define relapse, which further hinders study comparisons. As such, further efforts towards consistently defining and characterizing acute MS relapse is required.

Few studies reported safety outcomes (IVMP and RCI studies only). In addition, no QOL outcomes were reported for RCI, PMP, and IVIG. A similar exploration of realworld studies reporting outcomes for these second-line relapse therapies should also be aggregated to supplement these conclusions and to inform targeted evidence generation efforts.

\section{Conclusions}

This SLR, which focused on the highest quality studies (RCTs) evaluating relapse therapies for acute MS relapse (IVMP, RCI, PMP, IVIG), revealed several key findings: First, IVMP, an FDA-approved treatment for MS relapses, was shown to be a largely effective relapse treatment option. ${ }^{34-38,51}$ Next, while IVIG may be used as a treatment for MS exacerbations, it appears to be of limited clinical benefit in the studies identified, having no robust efficacy or safety data to support use as monotherapy in MS relapse. Similarly, data to support the efficacy and safety of PMP as monotherapy for MS relapses were also not available. Lastly, RCI is an approved, well-tolerated therapy with demonstrated efficacy in acute MS relapse. This therapy affords flexibility in administration compared with other second-line relapse therapies. 
As noted above, the smaller number of RCTs available for RCI and the absence of those for IVIG and PMP monotherapy (particularly with regards to safety and QOL data), as well as the heterogeneity in study outcomes, assessment time points, patient populations, treatment regimens and acute MS relapse definitions, made it difficult to formulate conclusions. Robustly designed and powered studies integrating safety, efficacy and patientcentered endpoints are needed to supplement the existing body of information.

\section{Article highlights}

- RCTs confirm IVMP and RCI are efficacious for the treatment of acute MS relapse

- RCI is a well-documented and supported treatment relative to IVIG and PMP

- The benefit of IVIG and PMP in treating acute relapses in MS is unclear

- IVMP, RCI and IVIG are well tolerated; no safety data for PMP are available

- QOL data are only available for IVMP, and show improvement

\section{Acknowledgments}

This work was supported by fund from Mallinckrodt Pharmaceuticals.

\section{Disclosure}

Jessica Costello, Annete Njue, Matthew Lyall, and Anne Heyes were employees of RTI Health Solutions at the time this SLR was developed and provided consulting services to Mallinckrodt Pharmaceuticals. Nancy Mahler is an employee of Mallinckrodt Pharmaceuticals. Tara Nazareth and Michael Philbin were employees of Mallinckrodt Pharmaceuticals at the time this work was done. The authors report no other conflicts of interest in this work.

\section{References}

1. Trapp BD, Nave KA. Multiple sclerosis: an immune or neurodegenerative disorder? Аnпи Rev Neurosci. 2008;31:247-269. doi:10.1146/ annurev.neuro.30.051606.094313

2. Filippini G, Brusaferri F, Sibley WA, et al. Corticosteroids or ACTH for acute exacerbations in multiple sclerosis. Cochrane Database Syst Rev. 2000;(4):CD001331.

3. Lublin FD, Baier M, Cutter G. Effect of relapses on development of residual deficit in multiple sclerosis. Neurology. 2003;61(11):15281532. doi:10.1212/01.wnl.0000096175.39831.21

4. Bernard JT. Treating Acute Relapses in MS. CME released. MedScape; March 17, 2015. Available from: https://www.medscape.org/viewarti cle/839227. Accessed June 14, 2019.
5. Food and Drug Administration. SOLU-MEDROL® (Methylprednisolone Sodium Succinate for Injection, USP). FDA; 2011. Available from: https://www.accessdata.fda.gov/drugsatfda docs/label/2011/011856s103s104lbl.pdf. Accessed June 14, 2019.

6. Acthar prescribing information. H. P. Acthar Gel for Intramuscular/ Subcutaneous Use. Mallinckrodt Pharmaceuticals; January 2015. Available from: https:/www.accessdata.fda.gov/drugsatfda_docs/ label/2010/022432s000lbl.pdf. Accessed June 14, 2019.

7. Cortese I, Chaudhry V, So YT, Cantor F, Cornblath DR, Rae-Grant A. Evidence-based guideline update: plasmapheresis in neurologic disorders: report of the Therapeutics and Technology Assessment Subcommittee of the American Academy of Neurology. Neurology. 2011;76(3):294-300. doi:10.1212/WNL.0b013e318207b1f6

8. Schwartz J, Padmanabhan A, Aqui N, et al. Guidelines on the use of therapeutic apheresis in clinical practice-evidence-based approach from the Writing Committee of the American Society for Apheresis: the seventh special issue. J Clin Apher. 2016;31(3):149162. doi: $10.1002 /$ jca. 21470

9. Scheinfeld N. Intravenous Immunoglobulin. Medscape; 2016.

10. Food and Drug Administration. Immune Globulin Intravenous (IGIV) Indications. FDA; 2018.

11. Nickerson M, Marrie RA. The multiple sclerosis relapse experience: patient-reported outcomes from the North American Research Committee on Multiple Sclerosis (NARCOMS) Registry. BMC Neurol. 2013;13:119. doi:10.1186/1471-2377-13-202

12. Stoppe M, Busch M, Krizek L, Then Bergh F. Outcome of MS relapses in the era of disease-modifying therapy. BMC Neurol. 2017;17(1):151. doi:10.1186/s12883-017-0927-x

13. Berkovich R. Treatment of acute relapses in multiple sclerosis. Neurotherapeutics. 2013;10(1):97-105. doi:10.1007/s13311-012-0160-7

14. National Multiple Sclerosis Society. Relapse Management. National Multiple Sclerosis Society; 2009.

15. National Multiple Sclerosis Society. Recommendations regarding Corticosteroids in the Management of Multiple Sclerosis. National Multiple Sclerosis Society; 2008.

16. Goodin DS, Frohman EM, Garmany GP Jr., et al. Disease modifying therapies in multiple sclerosis: report of the Therapeutics and Technology Assessment Subcommittee of the American Academy of Neurology and the MS Council for Clinical Practice Guidelines. Neurology. 2002;58(2):169-178. doi:10.1212/wnl.58.2.169

17. Hogg RV, Tanis EA, Zimmerman DL. Probability and Statistical Inference. Ninth ed. Boston: Pearson Education, Inc.; 2014.

18. NICE. Single Technology Appraisal: User Guide for Company Evidence Submission Template. London: National Institute for Health and Care Excellence; 2015.

19. NICE. Single Technology Appraisal. London: National Institute for Health and Care Excellence; 2012.

20. Kurtzke JF. Rating neurologic impairment in multiple sclerosis: an expanded disability status scale (EDSS). Neurology. 1983;33 (11):1444-1452. doi:10.1212/wnl.33.11.1444

21. U.S. Department of Veterans Affairs. Kurtzke Expanded Disability Status Scale. 2018.

22. Collins CDE, Ivry B, Bowen JD, et al. A comparative analysis of patient-reported expanded disability status scale tools. Mult Scler. 2016;22(10):1349-1358. doi:10.1177/1352458515616205

23. Milligan NM, Newcombe R, Compston DA. A double-blind controlled trial of high dose methylprednisolone in patients with multiple sclerosis: 1. Clinical effects. J Neurol Neurosurg Psychiatry. 1987;50 (5):511-516. doi:10.1136/jnnp.50.5.511

24. Durelli L, Baggio GF, Bergamasco B, et al. Early immunosuppressive effect of parenteral methylprednisolone in the treatment of multiple sclerosis. Acta Neurol (Napoli). 1985;7(3-4):338-344.

25. Durelli L, Cocito D, Riccio A, et al. High-dose intravenous methylprednisolone in the treatment of multiple sclerosis: clinical-immunologic correlations. Neurology. 1986;36(2):238-243. doi:10.1212/ wn1.36.2.238 
26. Filipovic SR, Drulovic J, Stojsavljevic N, Levic Z. The effects of highdose intravenous methylprednisolone on event-related potentials in patients with multiple sclerosis. J Neurol Sci. 1997;152(2):147-153.

27. Fierro B, Salemi G, Brighina F, et al. A transcranial magnetic stimulation study evaluating methylprednisolone treatment in multiple sclerosis. Acta Neurol Scand. 2002;105(3):152-157.

28. Oliveri RL, Valentino P, Russo C, et al. Randomized trial comparing two different high doses of methylprednisolone in MS: a clinical and MRI study. Neurology. 1998;50(6):1833-1836. doi:10.1212/wnl.50.6.1833

29. La Mantia L, Eoli M, Milanese C, Salmaggi A, Dufour A, Torri V. Double-blind trial of dexamethasone versus methylprednisolone in multiple sclerosis acute relapses. Eur Neurol. 1994;34(4):199-203. doi:10.1159/000117038

30. La Mantia L, Milanese C, Salmaggi A, Eoli M, Ciusani E, Nespolo A. Double blind randomized trial of dexamethasone high dose methylprednisolone and low dose methylprednisolone in multiple sclerosis bouts.J Neurology. 1990;237(Suppl 1):S20.

31. Chataway J, Porter B, Riazi A, et al. Home versus outpatient administration of intravenous steroids for multiple-sclerosis relapses: a randomised controlled trial. Lancet Neurol. 2006;5(7):565-571. doi:10.1016/S1474-4422(06)70450-1

32. Glass-Marmor L, Paperna T, Ben-Yosef Y, Miller A. Chronotherapy using corticosteroids for multiple sclerosis relapses. J Neurol Neurosurg Psychiatry. 2007;78(8):886-888. doi:10.1136/jnnp.2006.104000

33. Schmitt E, Behm E, Buddenhagen F, et al. Immunoadsorption (IA) versus plasma exchange (PE) in multiple sclerosis - first results of a double blind controlled trial. Prog Clin Biol Res. 1990;337:289-292.

34. Ramo-Tello C, Grau-Lopez L, Tintore M, et al. A randomized clinical trial of oral versus intravenous methylprednisolone for relapse of MS. Mult Scler. 2014;20(6):717-725. doi:10.1177/1352458513508835

35. Martinelli V, Rocca MA, Annovazzi P, et al. A short-term randomized MRI study of high-dose oral vs intravenous methylprednisolone in MS. Neurology. 2009;73(22):1842-1848. doi:10.1212/ WNL.0b013e3181c3fd5b

36. Le Page E, Veillard D, Laplaud DA, et al. Oral versus intravenous high-dose methylprednisolone for treatment of relapses in patients with multiple sclerosis (COPOUSEP): a randomised, controlled, double-blind, non-inferiority trial. Lancet. 2015;386(9997):974-981. doi:10.1016/S0140-6736(15)61137-0

37. Barnes D, Hughes RA, Morris RW, et al. Randomised trial of oral and intravenous methylprednisolone in acute relapses of multiple sclerosis. Lancet. 1997;349(9056):902-906.

38. Alam S, Kyriakides T, Lawden M, Newman P. Methylprednisolone in multiple sclerosis: a comparison of oral with intravenous therapy at equivalent high dose. J Neurol Neurosurg Psychiatry. 1993;56 (11):1219-1220. doi:10.1136/jnnp.56.11.1219

39. Grau-Lopez L, Tintore M, Ramio-Torrenta L, et al. Relationship between relapses and quality of life in patients with relapsing remitting multiple sclerosis. Mult Scler J. 2014;20:420.

40. Najmi Varzaneh F, Najmi Varzaneh F, Azimi AR, Rezaei N, Sahraian MA. Efficacy of combination therapy with erythropoietin and methylprednisolone in clinical recovery of severe relapse in multiple sclerosis. Acta Neurol Belg. 2014;114(4):273-278. doi:10.1007/ s13760-014-0286-y

41. Sorensen PS, Haas J, Sellebjerg F, Olsson T, Ravnborg M, Group TS. IV immunoglobulins as add-on treatment to methylprednisolone for acute relapses in MS. Neurology. 2004;63(11):2028-2033. doi:10.1212/01.wnl.0000145798.61383.39
42. Visser LH, Beekman R, Tijssen CC, et al. A randomized, doubleblind, placebo-controlled pilot study of i.v. immune globulins in combination with i.v. methylprednisolone in the treatment of relapses in patients with MS. Mult Scler. 2004;10(1):89-91. doi:10.1191/ $1352458504 \mathrm{~ms} 978 \mathrm{sr}$

43. Weiner HL, Dau PC, Khatri BO, et al. Double-blind study of true vs. sham plasma exchange in patients treated with immunosuppression for acute attacks of multiple sclerosis. Neurology. 1989;39(9):11431149. doi:10.1212/wnl.39.9.1143

44. Weiner HL, Dau PC, Khatri BO, et al. Double-blind study of true vs. sham plasmapheresis in patients being treated with immunosuppression for acute attacks of multiple sclerosis. Prog Clin Biol Res. 1990;337:283.

45. Henderson WG, Tourtellotte WW, Potvin AR, Rose AS. Methodology for analyzing clinical neurological data: ACTH in multiple sclerosis. Clin Pharmacol Ther. 1978;24(2):146-153. doi:10.1002/cpt1978242146

46. Rose AS, Kuzma JW, Kurtzke JF, Sibley WA, Tourtellotte WW. Cooperative study in the evaluation of therapy in multiple sclerosis: ACTH vs placebo in acute exacerbation. Trans Am Neurol Assoc. 1969;94:126-133.

47. Rose AS, Kuzma JW, Kurtzke JF, Namerow NS, Sibley WA, Tourtellotte WW. Cooperative study in the evaluation of therapy in multiple sclerosis. ACTH vs. placebo-final report. Neurology. 1970;20(5):1-59. doi:10.1212/wnl.20.5_part_2.1

48. Simsarian JP, Saunders C, Smith DM. Five-day regimen of intramuscular or subcutaneous self-administered adrenocorticotropic hormone gel for acute exacerbations of multiple sclerosis: a prospective, randomized, open-label pilot trial. Drug Des Devel Ther. 2011;5:381389. doi:10.2147/DDDT.S19331

49. Craig J, Young CA, Ennis M, Baker G, Boggild M. A randomised controlled trial comparing rehabilitation against standard therapy in multiple sclerosis patients receiving intravenous steroid treatment. $J$ Neurol Neurosurg Psychiatry. 2003;74(9):1225-1230. doi:10.1136/ jnnp.74.9.1225

50. Meyer-Moock S, Feng YS, Maeurer M, Dippel FW, Kohlmann T. Systematic literature review and validity evaluation of the Expanded Disability Status Scale (EDSS) and the Multiple Sclerosis Functional Composite (MSFC) in patients with multiple sclerosis. BMC Neurol. 2014;14:58. doi:10.1186/s12883-014-0196-x

51. Sharrack B, Hughes RA, Morris RW, et al. The effect of oral and intravenous methylprednisolone treatment on subsequent relapse rate in multiple sclerosis. J Neurol Sci. 2000;173(1):73-77.

52. Lal R, Bell S, Challenger R, et al. Pharmacodynamics and tolerability of repository corticotropin injection in healthy human subjects: a comparison with intravenous methylprednisolone. $J$ Clin Pharmacol. 2016;56(2):195-202. doi:10.1002/jcph.582

53. Benko A, Mcaloose C, Becker P, et al. Repository corticotrophin injection exerts direct acute effects on human $\mathrm{B}$ cell gene expression distinct from the actions of glucocorticoids. Clin Exp Immunol. 2018;192(1):68-81. doi: 10.1111/cei.13089.

54. Due B, Becker P, Coyle P. A prospective observational registry of repository corticotropin injection for the treatment of multiple sclerosis relapse: baseline characteristics and interim results. CMSC. 2017.

55. Perrin Ross A, Williamson A, Smrtka J, et al. Assessing relapse in multiple sclerosis questionnaire: results of a pilot study. Mult Scler Int. 2013:1-8. 


\section{Supplementary material MEDLINE search strategy}

Table SI MEDLINE literature search strategy, limited to english language

\begin{tabular}{|c|c|c|}
\hline Term group & $\begin{array}{l}\text { Search } \\
\#\end{array}$ & Search terms \\
\hline $\begin{array}{l}\text { Population of } \\
\text { interest } \\
\text { Interventions of } \\
\text { interest }\end{array}$ & $\# I$ & $\begin{array}{l}\text { “Multiple Sclerosis”[MeSH] OR “multiple sclerosis”[Text Word] OR “Multiple Sclerosis, Relapsing- } \\
\text { Remitting”[MeSH] } \\
\text { “Adrenocorticotropic Hormone”[MeSH] OR ACTH[Title/Abstract] OR A.C.T.H.[Title/Abstract] OR Acthar } \\
\text { [Title/Abstract] OR adrenocorticotropic hormone[Title/Abstract] OR corticotrophin[Title/Abstract] OR corti- } \\
\text { cotropin[Title/Abstract] OR adrenocorticotropin[Title/Abstract] OR “Anti-Inflammatory Agents”[MeSH] OR } \\
\text { “Methylprednisolone”[MeSH] OR methylprednisolone[Title/Abstract] OR prednisone[Title/Abstract] OR solu- } \\
\text { medrol[Title/Abstract] OR Solu-Medrol[Title/Abstract] OR IVMP[Title/Abstract] OR "Immunoglobulins, } \\
\text { Intravenous"[MeSH] OR intravenous immunoglobulin[Title/Abstract] OR immunoglobulin[Title/Abstract] OR } \\
\text { "Plasmapheresis”[MeSH]) OR "Plasma Exchange”[MeSH] OR plasmapheresis[Title/Abstract] OR plasma } \\
\text { exchange[Title/Abstract] OR immunoadsorption[Title/Abstract] }\end{array}$ \\
\hline $\begin{array}{l}\text { Study type (clinical } \\
\text { trials) }{ }^{\text {a }}\end{array}$ & \#3 & 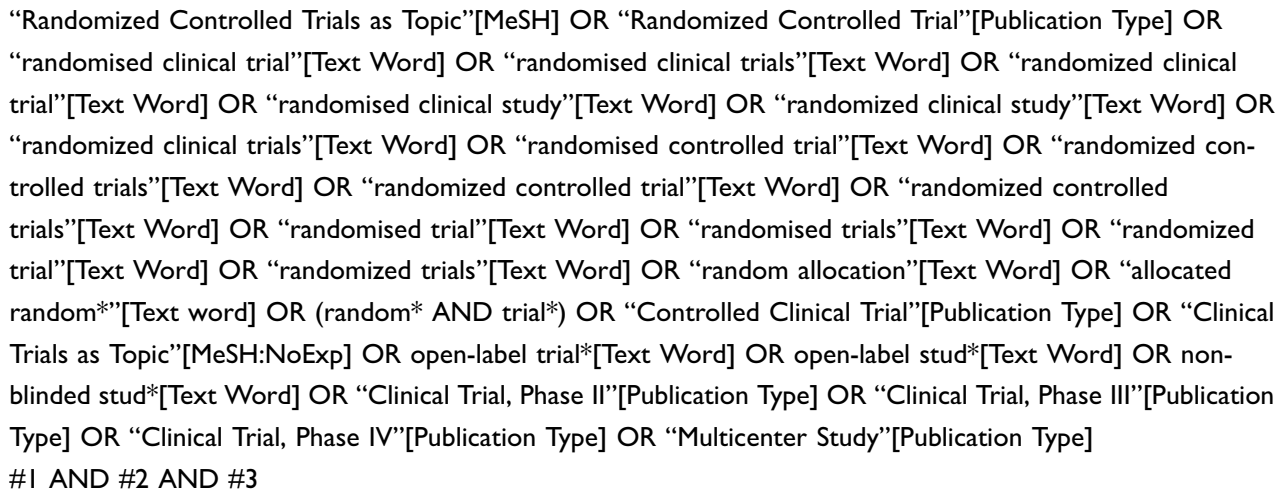 \\
\hline Exclusion terms & $\begin{array}{l}\# 5 \\
\# 6\end{array}$ & $\begin{array}{l}\text { "Animals"[MeSH] NOT "Humans"[MeSH] } \\
\text { "Clinical Trial, Phase I"[Publication Type] OR "Clinical Trials, Phase I as Topic"[MeSH] OR } \\
\text { "Comment"[Publication Type] OR "Editorial”[Publication Type] OR "Letter"[Publication Type] OR } \\
\text { "Guideline"[Publication Type] OR "Guidelines as Topic"[MeSH] OR "prognostic"[Text Word] OR animal model* } \\
\text { [Text Word] OR "Case Reports"[Publication Type] OR case report*[Text Word] OR "case series"[Text Word] } \\
\text { OR "case study"[Text Word] OR "case studies"[Text Word] } \\
\text { \#4 NOT (\#5 OR \#6) No date limits } \\
\text { \#7, limited to English language }\end{array}$ \\
\hline
\end{tabular}

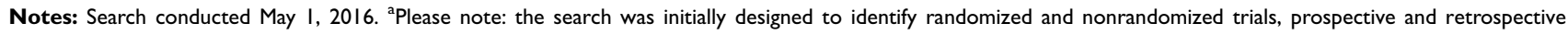
studies; however, for the purposes of this manuscript, which focuses on RCTs, selection of full texts during level 2 screen was limited to RCTs only. The search strategy for PubMed therefore reflects this and presents terms for RCTs only.

Abbreviation: RCT, randomized controlled trial.

Degenerative Neurological and Neuromuscular Disease

\section{Dovepress}

\section{Publish your work in this journal}

Degenerative Neurological and Neuromuscular Disease is an international, peer-reviewed, open access journal focusing on research into degenerative neurological and neuromuscular disease, identification of therapeutic targets and the optimal use of preventative and integrated treatment interventions to achieve improved outcomes, enhanced survival and quality of life for the patient. The manuscript management system is completely online and includes a very quick and fair peer-review system. Visit http://www.dovepress.com/ testimonials.php to read real quotes from published authors. 